\title{
A Review of Current Methods in Microfluidic Device Fabrication and Future Commercialization Prospects
}

\author{
Bruce K. Gale *(i), Alexander R. Jafek ${ }^{(\mathbb{D})}$, Christopher J. Lambert ${ }^{(\mathbb{D}}$, Brady L. Goenner, \\ Hossein Moghimifam, Ugochukwu C. Nze ${ }^{(D)}$ and Suraj Kumar Kamarapu (D) \\ Department of Mechanical Engineering, University of Utah, Salt Lake City, UT 84112, USA; \\ a.jafek@gmail.com (A.R.J.); chris.lambert@utah.edu (C.J.L.); bradygoenner@gmail.com (B.L.G.); \\ h.moghimifam@utah.edu (H.M.); u.c.nze@utah.edu (U.C.N.); suraj.kumar@utah.edu (S.K.K.) \\ * Correspondence: bruce.gale@utah.edu; Tel.: +1-801-585-5944
}

Received: 30 June 2018; Accepted: 20 August 2018; Published: 28 August 2018

\begin{abstract}
Microfluidic devices currently play an important role in many biological, chemical, and engineering applications, and there are many ways to fabricate the necessary channel and feature dimensions. In this review, we provide an overview of microfabrication techniques that are relevant to both research and commercial use. A special emphasis on both the most practical and the recently developed methods for microfluidic device fabrication is applied, and it leads us to specifically address laminate, molding, 3D printing, and high resolution nanofabrication techniques. The methods are compared for their relative costs and benefits, with special attention paid to the commercialization prospects of the various technologies.
\end{abstract}

Keywords: microfabrication; nanofabrication; microfluidics; nanofluidics; 3D printing; laminates; molding

\section{Introduction}

Microfluidics is a growing field of research which pertains to the manipulation of fluids on the microscale level, and it is identified most commonly by devices with critical dimensions of less than $1 \mathrm{~mm}$. At this scale, researchers can take advantage of the scaling of many physical laws and employ, for example, rapid diffusion [1], laminar flows [2], Dean flow [3], rapid thermal transport [4], and take advantage of the large surface area relative to the volume [5]. These varied benefits have helped microfluidics find applications in many fields including analytical chemistry [4], energy generation [6], cell separations [3], and molecular biology [7]. As the field has progressed, many different methods have emerged for fabricating channels with the requisite dimensions.

Much of the work in the field of microfluidics was performed using soft lithography as introduced by Whitesides [8] in 1998. The methods for soft lithography, especially in polydimethylsiloxane (PDMS), have been well documented [9-11]. One of the principal difficulties of soft lithography originally was the requirement for cleanroom fabrication which, while well-developed by the microelectromechanical Systems (MEMS) community, remains costly and time-consuming. This has been overcome to some degree recently with low-cost mold making methods, as covered by Faustino [12]. Microfluidic engineers have developed a variety of methods for fabricating submillimeter channels aside from soft lithography for various reasons, including decreased cost, faster turnaround time, cheaper materials and tools, and increased functionality. These developments have allowed microfluidic devices to be fabricated using a wide range of materials and geometries, enabling new and advantageous physical behaviors and qualities in microfluidic devices. 
In this work, we provide an overview and comparison of several key fabrication techniques that are employed in microfluidic research today. These techniques include polymer laminates, 3D printing approaches, various polymer molding technologies, and recent developments in nanofabrication.

It has been our experience that starting a project with the correct fabrication technique can significantly accelerate a project's timeline and improve the performance of the given device. This work specifically focuses on channel-based microfluidics, as opposed to paper-based devices. A helpful review of paper-based devices can be found [13]. Further, this work also aims to cover those fabrication methods that do not require soft lithography. It builds upon other work such as the recent review by Walsh [14] which offers a good review of fabrication techniques available for makerspace creators and has an emphasis on recent microfluidic applications and demonstrations.

\section{Laminates}

Here we describe laminate microfluidic devices as chips, which are created as a stack of independently cut layers which are bonded together to form channels and microfluidic features. In these devices, each layer can be thought of in a two-dimensional flow geometry, which is closed by the layers above and below them. The height of a channel is then defined by the thickness of the material that is used to form the layer.

The most simplistic layered device is one composed of three layers: an interface layer, a flow layer, and a bottom layer [15]. As an example, a three-layer device, used for microfluidic polymerase chain reaction PCR, is shown in Figure 1. The device is fabricated by stacking a microscope slide, a flow layer cut from double-sided tape, and a microscope slide with ports cut into it, to form a closed channel [4] with acrylic ports glued on as interfaces. This example illustrates many of the benefits of layered microfluidic devices in a laboratory/prototyping setting: relatively inexpensive materials and instruments, simple process steps, rapid fabrication times, well-controlled layer depths (set by material thickness), optical access, and submillimeter feature sizes. With the possible exception of 3D printing, layered devices are the fastest and easiest way to fabricate microfluidic channels for most applications. While fabrication is simple and rapid, available laboratory cutting methods generally limit feature widths to 50-200 $\mu \mathrm{m}$, which may not be small enough for some microfluidic applications.

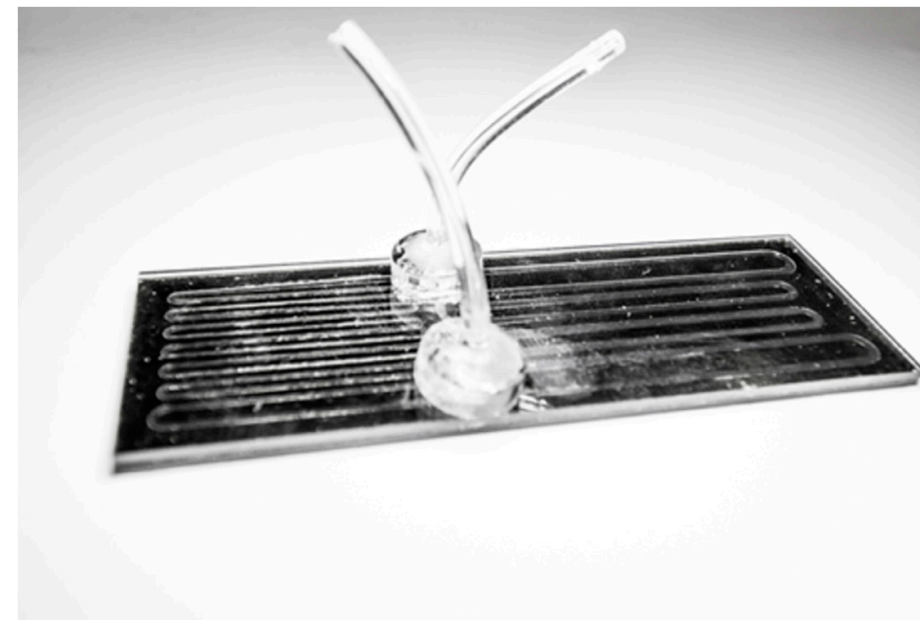

Figure 1. Device for xPCR fabricated with double-sided adhesive tape sandwiched between two glass slides [4].

The four principal steps in forming a laminate device are (1) material selection, (2) cutting the desired microfluidic features in each layer, and (3) bonding the independent layers together to form one functioning device. Here, we provide a list of existing technologies in each of these areas with the intention of providing a resource for those hoping to fabricate such devices. 
Laminate manufacturing methods are compatible with a very broad range of materials. Generally, a wide range of optically clear plastics and thermoplastics can be employed with laminates, as well as opaque layers, as desired. Three very common material categories in laminate device construction are adhesive transfer tapes [16], polymer layers (commonly polycarbonate, PMMA, and COC) [17], and glass slides. Adhesive transfer tapes are advantageous because the bonding is inherent in the material, although they may have the problem of chemical or particle absorption. Walsh et al. have compiled a valuable list of recommended adhesive transfer tapes for those looking to get started in the space [14]. Polymers (including acrylic and polycarbonate) and glass layers are common for many of the same reasons: optical clarity, low cost, and sample compatibility. While these are the three most common materials, an immense number of other materials can be employed in laminate manufacturing. Indeed, due to their compatibility with so many different forms of bonding (including simple adhesives) laminate manufacturing is the fabrication method that is compatible with the widest variety of materials.

For laminate microfluidic devices, each layer is cut individually. The cutting method has a significant impact on the dimensions and the device functionality. For prototyping and laboratory settings, cutting is usually done with a knife plotter (i.e., xurography) or laser cutter because of the speed and simplicity that each tool offers. A knife plotter works by precisely cutting a material with a blade to create the geometry, while a laser cutter uses a focused beam (traditionally $\mathrm{CO}_{2}$ lasers are used). In both methods, the general process overview is the same: a device is designed using CAD software, the device geometry is cut using the selected method, the inner portion is cleaned ("weeding"), and the layers of the device are bonded together to form closed channels. In choosing between these two methods, the decision can be made based on the materials that will be employed, the thickness of the layers, and the dimensional accuracy required. A general review of this decision is available elsewhere [14].

In general, laser cutters offer a better resolution (offering dimensional accuracy as small as $25 \mu \mathrm{m}$ with optimized materials), and are more flexible in the materials and thicknesses with which they are able to work [18]. However, they are in general much more costly (>USD \$10,000). For the laboratory and prototyping setting, Walsh, et al. offers a good review of the general benefits and costs associated with each cutting method [14]. Besides the monetary cost of laser cutting, laser processing requires a vacuum pumping system, and it may leave burn residue that could impede the performance of the device. Cutting with a knife plotter is generally easier to set up than a laser cutter (it is less expensive and does not require a vacuum system), but less resolution is available (cutting features smaller than $500 \mu \mathrm{m}$ can be challenging on some systems), materials and thicknesses are more limited, and more setup time may be required to determine the optimal parameters. Once running, the time required for cutting each piece is similar between a knife plotter and laser cutter. For many applications, the two cutting methods perform similarly, and a selection can be made based on the availability of instruments [16].

Although the selection of the bonding method is inherently tied to the materials employed in the fabrication method, two of the most common and straightforward bonding methods are adhesives and thermal bonding. When employing adhesives as the bonding method, double-sided tape can be cut and employed directly as the flow layer or an adhesive layer can be applied between layers of different materials. This second method significantly increases the variety of materials that can be employed as adhesives are able to hold together most materials. While adhesive bonding is a significant enabling method, devices that employ adhesive bonding traditionally struggle to maintain high pressures (beyond 5 bar), and can be prone to uneven bonding and channel heights [19]. In some cases, the pressure that can be sustained by adhesive-bonded devices can be increased. Demonstrated methods include plasma treating the surfaces before they are brought together, and the application of heat and pressure after the layers have been brought together [17].

Thermal bonding is another straightforward bonding method which is commonly employed in microfluidic devices. To facilitate thermal bonding, the temperature of the individual layers is 
elevated to a temperature that is near the glass transition temperature of one or both of the materials, and a force is applied across the surface of the layers. When performed properly, the individual layers form one essentially indistinguishable solid material. While thermal bonding is not possible with all materials, it is particularly useful with polycarbonate and polylactic acid (PLA). The main disadvantage of thermal bonding is the possible warping of features from the heating or as the device cools down. Some laminating processes also leave bubbles between the layers. The compatibility of laminate microfluidics with thermal bonding often blurs the line between thermoplastic and laminate microfluidic manufacturing.

Since the layers of a microfluidic device are created one at a time, aligning the individual layers is an important preparation step for the bonding process. Many, if not all, device fabrication protocols include either an alignment step or an alignment tool used to prepare for this, with alignment holes of features being created in each of the individual layers in the cutting step.

The bonding method has a very significant impact on the pressure that the device is able to withstand, and this can significantly affect device performance. Poor bonding is also the source of many problems that plague layered devices, including the presence of air bubbles between layers (leading to leakage) and the deformation of features in the microfluidic device, which can seriously degrade device performance.

One of the primary benefits of laminate fabrication relative to other fabrication techniques is its scalability, especially when quantities exceed $\sim 100,000$ devices. Lamination is especially scalable because each individual fabrication step can be automated and run in a massively parallelized fashion. For example, as fabrication is pushed to commercial scales, individual layers could be cut through a stamping method. In a streamlined fabrication method, this cutting technique could prepare tens to thousands (UN6) of devices per minute. As device fabrication moves to this scale, fabricators could begin to take advantage of other modern microfluidic fabrication techniques. Such was the inspiration behind the concept of the Lab-on-a-foil fabrication, which employs and often blends thermoplastic and laminate based manufacturing methods to create devices characterized by cost-effective, high-volume fabrication, and self-contained disposable chips. Figure 2 shows what this fabrication method could look like at scale in a reel-to-reel processing scenario [20]. As microfluidics move towards large scale commercial production, laminate based manufacturing will certainly play an important role in the development.

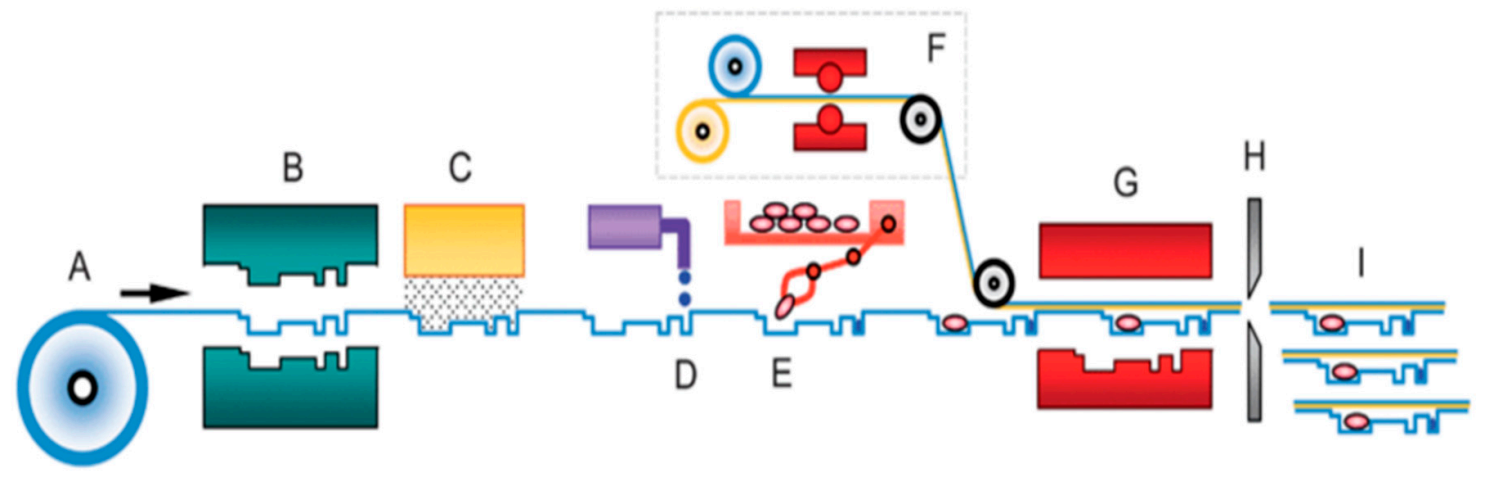

Figure 2. Schematic of a reel-to-reel processing scenario: (A) rolled foil; (B) structuring; (C) surface modification; (D) liquid dispenser; (E) pick-and-place station; (F) lamination of multilayer sealing foil; (G) sealing; (H) cutting; (I) final product [20].

Though lacking the same dimensional precision offered by other microfabrication techniques, layered devices offer a simple platform for incorporating complexity by increasing the number of layers used in the device and by incorporating other functional and sensing layers (filters [21], electrodes [22], etc.). The incorporation of microfluidic chips with multiple flow layers is paramount when preparing a true lab-on-a-chip platform. In an early demonstration of the utility of laminate 
microfluidic chips, Weigl et al. created a hematology cartridge, shown in Figure 3, which was used to process whole blood samples to determine red blood cell and platelet counts, hemoglobin concentration, and white cell differential count [23]. By fabricating the chip across multiple layers, the authors are able to incorporate inlets, multiple storage areas, and a micro-cytometer on the chip. The authors noted that a minimum of five layers are required when channels pass over each other, which begins to illustrate both the large number of layers that may be required for some applications (e.g., a flow focusing element requires five layers), and as a corollary, the importance of proper alignment and bonding.

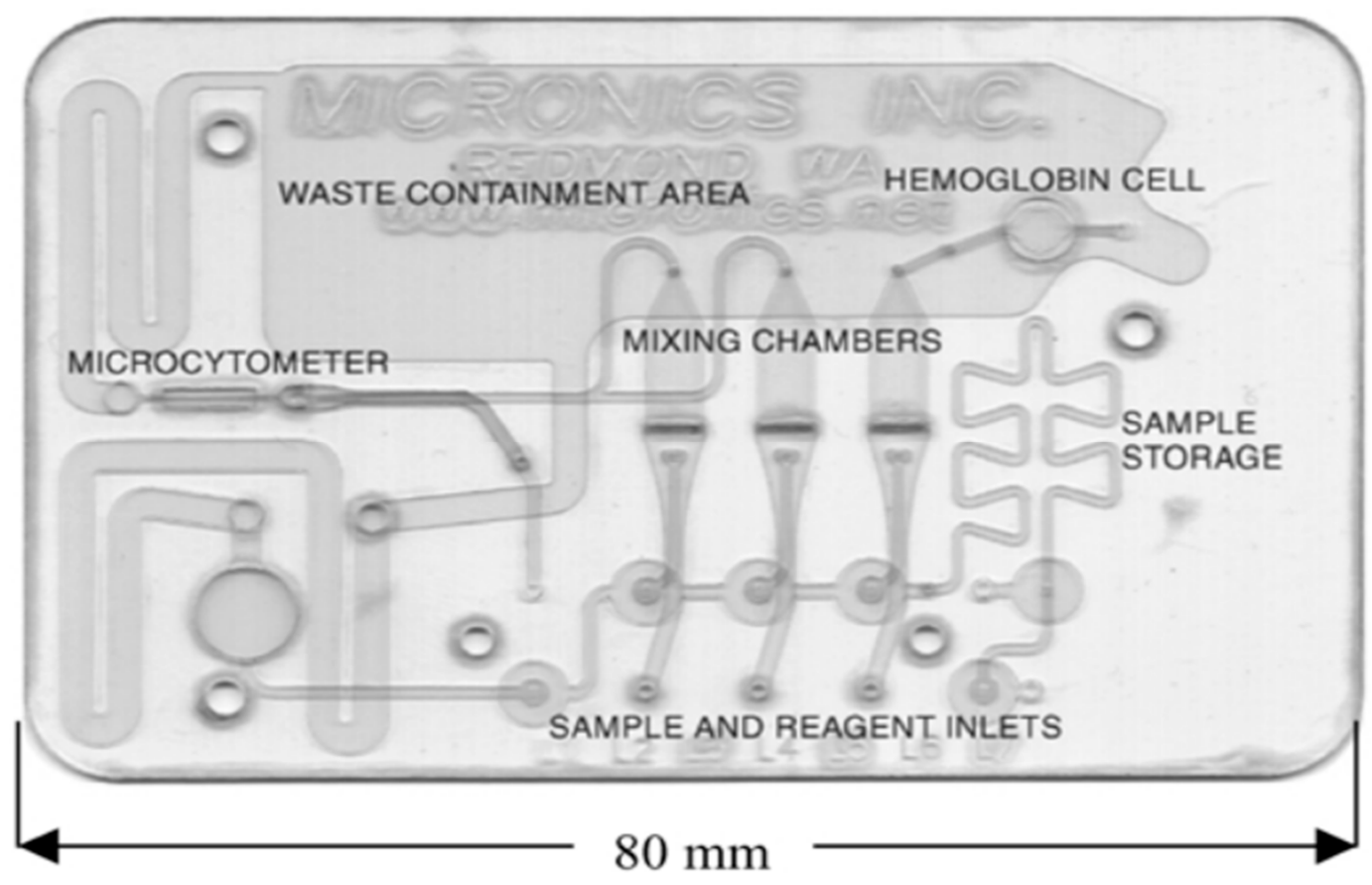

Figure 3. Microfluidic laminate device for whole blood processing [23].

\section{Molding}

Microfluidic fabrication based on molding can be segmented into three distinct classes: replica molding, injection molding, and hot embossing. The unique advantages and limitations of each method orient them toward accomplishing a particular need in research and commercial microfluidics. Current research aims to improve on past methods, and in some cases they generate new processes in order to innovate powerful solutions to complex challenges faced in microfluidics.

\subsection{Replica Molding}

Replica molding (i.e., soft lithography) was first introduced in 1998 by Xia and Whitesides [12]. The core of the technology relies on using photolithography to generate silicon and photoresist molds over which a liquid-set polymer such as PDMS is poured and cured. SU-8 is a common negative photoresist used in mold fabrication due to its high resolution, mold durability, and capacity for high aspect ratios [12]. The cured polymer is peeled from the mold surface, and it contains a replica of the mold. By bonding the mold with a glass slide, a closed channel is formed. This process utilizes techniques previously established in silicon-based fabrication processes. The replica molding process is portrayed in Figure 4 [24]. Since its inception, this technology has continued to grow in use, becoming a standard in the fabrication of microfluidic devices. In particular, this fabrication method found a particular home in biomedical microfluidics due to its incorporation of a high-resolution, flexible, optically transparent, biocompatible polymer, namely PDMS [12]. General techniques yield resolutions from a few microns to hundreds of nanometers. While such high resolutions require cleanroom facilities for mold fabrication, the introduction of rapid prototyping techniques brought low cost, 
non-cleanroom methods yielding resolutions as low as $10 \mu \mathrm{m}$ [25]. Nanoimprint lithography (NIL), a unique replica molding technique, has demonstrated resolutions in the sub-15 $\mathrm{nm}$ range [26].

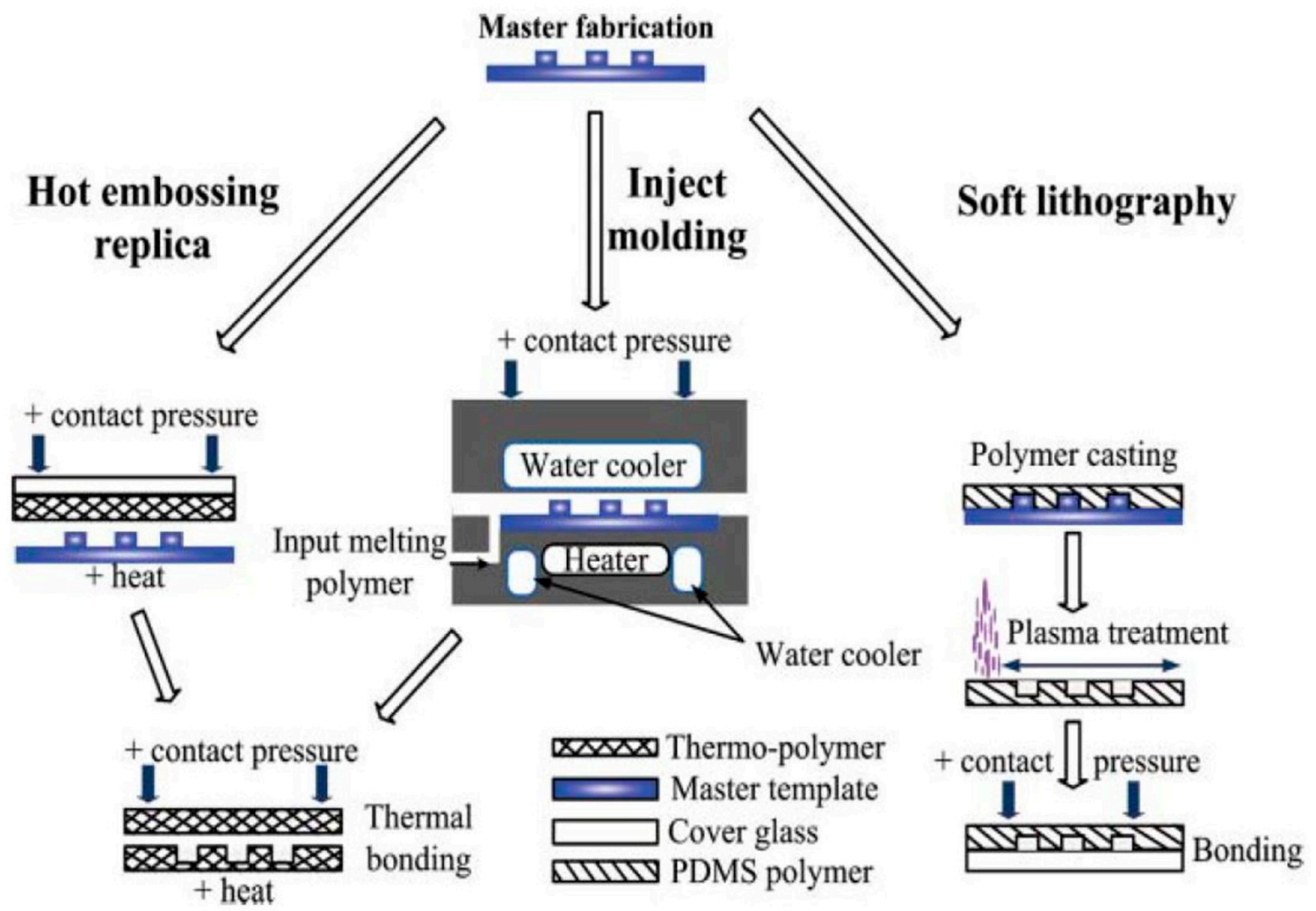

Figure 4. An illustration of the fundamental molding methods used in microfluidics [24].

Replica molding encompasses several unique variations. This includes techniques such as micro transfer molding, a process similar to ink stamping, where a "stamp" is loaded with a liquid-set polymer and transferred to another surface. This technology has seen successful applications in cell culturing as a method for generating a more biologically similar or "biomimetic" environment [27].

A key advantage of soft lithography includes high-resolution replicas, as well as three-dimensional geometries [12]. Another key advantage is the ability to stack multiple molded layers atop each other to generate intricate three-dimensional flows and pneumatic control lines. Limitations of general soft lithography techniques include pattern deformation of the mold and a potential for defects in molded polymers such as those that can occur when removing the cast from the mold [24]. General techniques require that molds not contain undercut or locations where the top feature of a mold is larger than its base-to-substrate contact point.

Over recent years, three-dimensional cell cultures have taken a prominent position in biomedical engineering. The capability to generate these structures is of great value to the biological modeling of vascular, cardiac, liver and brain biology; however, current methods are technically limited in resolution, cell viability, and especially in their ability to deliver fluidic control to the structure [28]. In 2017 Ugolini et al., combined general replication molding of PDMS with a novel method of structuring cell-laden hydrogels within microfluidic channels [28]. This approach demonstrates an innovative solution to providing fluid flow and to control to three-dimensional cell structures. The pursuit of fabricating biologically analogous in vitro models continues to be a focus for microfluidic research. Research conducted by Sticker et al. establishes the need for an alternative to PDMS membrane-integrated microfluidics, and provides convincing results for a unique material that is far better suited for multilayered membrane integrated microfluidics [29]. Sticker shows that PDMS 
membranes have significant limitations, including the high permeability of hydrophobic molecules, high compliance, and water vapor permeability. Sticker provides a thermoset alternative to PDMS, which addresses the limitations of conventional PDMS structures. Their research demonstrates the capability of this material to generate multi-layer, three-dimensional, multi-cell type structures more representative of their biological counterparts. This and similar research continue to refine our ability to replicate biologically similar models using microfluidics.

It seems probable that replica molding will continue to play a central role in research requiring custom microfluidic design. The versatility in design, simplicity in fabrication, biocompatibility, and integration potential of soft lithography techniques ensures longevity in research applications. Methods that previously required expensive and high maintenance cleanroom facilities are gradually being replaced by similar technologies not requiring a high cost. While this method is available for commercial products, it takes second place to thermoplastic options.

\subsection{Injection Molding}

Injection molding of microfluidics or, micro injection molding, was first developed in the 1980s [30]. Injection molding and its sister technology, hot embossing, utilize the wide range of available thermoplastics to generate high throughput, cost-efficient, and precise microfluidics. For this reason, these two techniques have found great favor commercially over other microfluidic fabrication methods. Micro injection molding occurs in four basic steps. First, the thermoplastic is precisely melted to a liquid state inside of a compressible chamber. Next, the two halves of the mold are compressed, creating a mold cavity. Then, the thermoplastic is injected at a specific rate, filling the mold cavity. Finally, the mold is cooled and the cast part is removed from the mold, as shown in Figure 4. A range of mold insert techniques and materials are available, and are selected based upon the required production life of the mold. Short term production needs to utilize silicon-based inserts, whereas long-term production generally uses metal inserts [30]. The resolution of molds and casts are dependent upon the method that is used to make the mold inserts. Micro milling of metal molds is generally on the order of $25 \mu \mathrm{m}$, whereas electron beam lithography has the potential to achieve sub-micron resolution [30]. Limitations of micro injection molding include material restriction to thermoplastics; mold features must not have undercuts or high mold fabrication costs [24].

A survey of recently published papers on micro injection molding illustrates the needs and directions that researchers aim to take, in order to further develop this technology. The two predominant research directions include the attempts to reduce the cost and time of mold fabrication or those that aim to improve the functionality of existing methods and materials. An example of the latter can be found in a 2017 research article published by Wiedemeier et al., who presented a method of fabricating a microtopography superhydrophobic surface layer during the injection molding process [31]. The value of such an improvement is applicable in droplet-based microfluidics, where precise formation and movement of liquid droplets is essential, and specifically, in the formation and movement of whole blood, a fluid which has been challenging to incorporate into droplet microfluidics [31].

Other research conducted by Szydzik et al. aims to improve the functionality of injection molded microfluidics by introducing a novel method of integrating complex fluid handling into existing methods [32]. They argue that improved fluid handling in injection molded microfluidics will be required in order for this technique's full potential to be realized in point-of-care diagnostics.

Further research aims to reduce the cost and time required to fabricate mold inserts. Two examples will be provided here. The first comes from Vereschchangina et al., which proposes a 3D printed mold insert that is capable of molding 100 parts without failure [33]. While this is not anywhere near the hundreds of thousands of cycles capable on some metal mold inserts, this direction shows great promise as an up-and-coming or even a potentially game-changing technology in 3D printing. In a similar, yet unique take on addressing the challenge of high-cost mold fabrication, 3D printed metal 
molds show the potential for the rapid production of metal mold inserts [34]. As this technology is refined, it will likely see applications in mold fabrication.

A strong presence of injection molding in commercial microfluidics is promising for the future of the technology [35]. Its high initial entry cost and overall cost-efficient production continue to make it well suited for commercialization of parts that need to be manufactured in large volumes. Research interest in addressing the limitations of this technology appears strong. We anticipate that innovations in 3D printing may compete, as printing times are reduced; however, injection molding will likely continue to hold an edge on high production rates for the foreseeable future.

\subsection{Hot Embossing}

Hot embossing is a process wherein thermoplastics, or polymers that become viscous liquids at elevated temperatures, are precisely shaped using a mold, pressure, and heat. Common thermoplastics used in microfluidics include polycarbonate, polymethylmethacrylate, cyclic olefin copolymer, and polyethylene terephthalate [35]. In this process, a thermoplastic film is placed between two mold inserts. Next, the mold chamber is evacuated, compressed, and heated, creating a cast of the mold. Finally, the mold is cooled and the cast is removed. The fundamental fabrication method is shown in Figure 4. Due to this technology's capacity for cost efficiency, precision, and high throughput, hot embossing has found widespread commercial adoption by microfluidic companies [24]. Hot embossing has several advantages over injection molding. Hot embossing requires the thermoplastic to flow a relatively small distance in comparison to injection molding. This significantly reduces the stress produced in the material [36]. Additionally, shrinkage of the cast is reduced, making this method effective in the fabrication of delicate designs [36]. Limitations of the technology include a restriction to thermoplastics, and difficulty in the fabrication of complex three-dimensional structures [24].

Advances in molding technology have enabled the fabrication of nanoscale devices. The draw to fabrication and research at this scale is directly related to the unique physical phenomena that occur only at the nanoscale. Scaling effects define a unique change in flow physics when moving from a macro scale to a microscale. Such a change in flow physics is also apparent when moving from the microscale to the nanoscale [37]. Intermolecular forces and electrokinetic effects move from a relatively minor contributor to nearly dominating, at the nanofluidic scale. It is interesting to note that most biological fluid processes function at the nanoscale, further garnering interest in this area of fluids research [37]. State of the art research is now focused on generating nanoscale fluidic geometries with dimensions in the sub-50 $\mathrm{nm}$ range, in thermoplastics using hot embossing to take advantage of the cost-efficient, high throughput, and disposability found in traditional hot embossing technology [35]. A particular application for thermoplastic nanochannels includes DNA analysis by DNA linearization. DNA linearization involves confining DNA along its length in a nanochannel. Genomic mapping, a process of labeling particular DNA sequences, can then be performed on linearized DNA [35]. In addition to genomic mapping, other applications including nanoelectrophoresis, electrochemical detection, and single nucleotide polymorphism identification methods are currently being pursued, using this technology [35].

Current research continues to build upon prior knowledge by improving on effective, but limited, technologies. One key limitation of hot embossing is the time consuming and expensive process of making molds. Using a unique modification of hot embossing known as hot intrusion embossing, Debono et al. created a one-step process for the fabrication of microfluidic channels containing complex three-dimensional structures in various thermoplastics [38]. Their use of a rapid template mold fabrication method enabled molding of sub-50 $\mu \mathrm{m}$ tapered posts, steps, and walls, as well as three-dimensional serpentine channels. The value of this technology is in its ability to reduce the cost of thermoplastic molding, making it more accessible by researchers and commercialization entities. In another recent publication, Lin et at present a 3D printed metal mold method for rapid production of metal mold inserts [34]. While metal 3D printing is still in its infancy, it will undoubtedly become 
more feasible as this technology develops. This article illustrates the proof of concept for this method and demonstrates the potential for overcoming current limitations of hot embossing.

Due to its capacity for high throughput, cost-efficient, and precise molding, hot embossing will likely continue to be an excellent option for commercial microfluidics. This method is also expected to gain momentum in research lab settings as mold and fabrication costs are reduced. Additionally, hot embossing seems ready to play a major role in making nanofluidic fabrication available at a significantly lower cost, as interest in this realm of physics increases [35].

\section{3D Printing}

3D printing is a layer-by-layer manufacturing technology, in which a new layer of material is added on top of the previous layer. The general process uses a 3D digital model that is sliced into layers, which can be interpreted and created by the printer. 3D printing technologies have a fascinating potential for microfluidic researchers, and can be easily used for prototyping. There are different technologies associated with 3D printing. In this section, we will focus on fused deposition modeling (FDM), stereolithography (SL), multijet modeling, and two-photon polymerization, and we explore their capabilities relative to microfluidic device fabrication.

\subsection{Fused Deposition Molding}

Fused deposition modeling (FDM) is the most common extrusion-based 3D printing technology. Extrusion-based methods use a nozzle to print different layers of 2D planes on top of each other. In FDM, the material is melted in the nozzle, and then it is extruded onto the previous layer, where it binds before cooling. With the expiration of the original patent, many companies have improved and optimized the technology, resulting in a low-cost method available with a variety of applications. Today, a desktop 3D printer, which uses this technology, can be bought for as little as $\$ 200$. Another merit of this technology is its ability to use a variety of biocompatible thermoplastics such as acrylonitrile butadiene styrene (ABS), PLA, polycarbonate, polyamide, and polystyrene [39]. Besides these conventional materials, composite materials such as reinforced polymer composites and nanocomposites can also be utilized [40]. FDM is also capable of printing multi-material objects, one of which is usually a sacrificial material [40]. In many applications, it can be the best choice due to its low cost, small space requirements, high speed, and manufacturing ease.

The use of FDM in microfluidics goes back to 2002, when the Whitesides' group used an FDM printer to make a mold for PDMS casting [41]. However, FDM is not generally a well-suited method for microfluidic applications. In comparison to their injection-molded counterparts, FDM-printed blocks are more prone to compressive stress fracture, because the filaments from adjacent layers are not well fused [39]. FDM printing generates hazardous plastic fumes that would require ventilation systems in large-scale production factories [39]. Also, 3D printed parts are leak-prone, and filament sizes are relatively large for making microfluidic channels [42]. The ability of 3D-printed structures to be leak-proof is subject to the material, the extrusion parameters, the channel design, and the fluid used in the channel [39]. On the other hand, FDM technology is relatively cheap, and widely accessible. In another modification of FDM, liquid precursors are extruded through the nozzle without heating, which may be used as an inexpensive way to incorporate a variety of sensors and valves within microfluidic devices [39]. 
There have been numerous applications of FDM in microfluidics since Whitesides' group used a FDM printer to print a mold [41]. Moore et al. fabricated capillary valves in the centrifugal microfluidic disc using an FDM printer [43]. They showed that the patterned surfaces produced by 3D printing can be used as an alternative to photolithography and computer numerical control (CNC) machining. Symes et al. [44] produced a reusable, robust, and self-healing reaction device for organic and inorganic synthesis. The "reactionware", with built-in catalyst, was built via an extrusion printer using an acetoxy silicone polymer. The device enabled in situ monitoring of the reaction. The reactor was printed using FDM loaded with the starting materials, reagents, and catalysts. They reported that they built the same device as could have been built using glassware, but with notably reduced chemical handling and specialized equipment during the synthesis and the subsequent purification step. Cronin's group made reactionware with channels of $0.8 \mathrm{~mm}$ in diameter, and a total reaction volume of $60 \mu \mathrm{L}$, using polypropylene [45]. They modified an extrusion-based 3D printer to extrude melted sugar (maltitol) to print the sacrificial sugar mold on top of a PDMS sublayer. Then, the PDMS was cast on the sugar layer. During the post-printing procedure, the device was drowned in boiling water, which dissolved the sugar layer and formed the microfluidic channels [46]. Bhargava and coworkers used epoxy resin as the casting material, and isomalt, a sugar alcohol that melts above $195^{\circ} \mathrm{C}$, as the sacrificial scaffold, which was dissolved in aqueous solution after curing [47]. Kadimisetty et al. printed a cheap microfluidic immunosensor that could detect three prostate cancer biomarkers simultaneously in $35 \mathrm{~min}$ [48]. FDM has become popular due to the low cost of fabrication, which, though the process is limited to low melting thermoplastics, has limited resolution, and lacks control of surface roughness when compared to other $3 \mathrm{D}$ printing processes such as stereolithography.

\subsection{Stereolithography}

SL is a classic rapid prototyping technique that works through an optical process that builds layer on layer. Stereolithography is ideal for creating very fine features in a rapid manner. SL uses a vat of resin that is polymerized using a structured light source to develop each layer. The use of UV light is very common in SL, though some resins can be developed using longer wavelengths. This dependence on the polymerization wavelength is associated with the type of photoinitiators mixed with the photopolymer to crosslink the polymer chains.

The two common ways of exposing the photopolymer to light are by using SLA and digital light processing (DLP). SLA apparatuses use a focused light-emitting diode (LED) laser and scanning galvano-mirror to cure spots at the surface of the vat. This technique is used in many commercial printers. Another, more common method for custom-built 3D printers, uses a DLP projector. This technique exposes the entire surface simultaneously, and projects a pattern that is masked using digital micromirror display technology (DMD).

The process of layering can be done from two different approaches: "Free Surface" configurations and "Constrained Surface" configurations [42] (Figure 5A,B). The "Constrained Surface" is by far the most popular for current stereolithography configurations because it avoids potential contamination and formation of oxides (which can be a potential inhibitor), as well as decreasing the amount of resin required for the development of a structure, as the "free surface" configuration requires the height of the bath to be the height of the structure. A potential issue that can arise is the surface distortion due to the forces experienced while lifting and peeling the structure off the vat surface. Common vat materials used are PDMS, FEP, and glass [49], to reduce the force experienced over the cured layer, which can also be used with tilting the vat or stage to further lower peeling forces. 
A. "Free Surface" Technique B. "Bat" Configuration
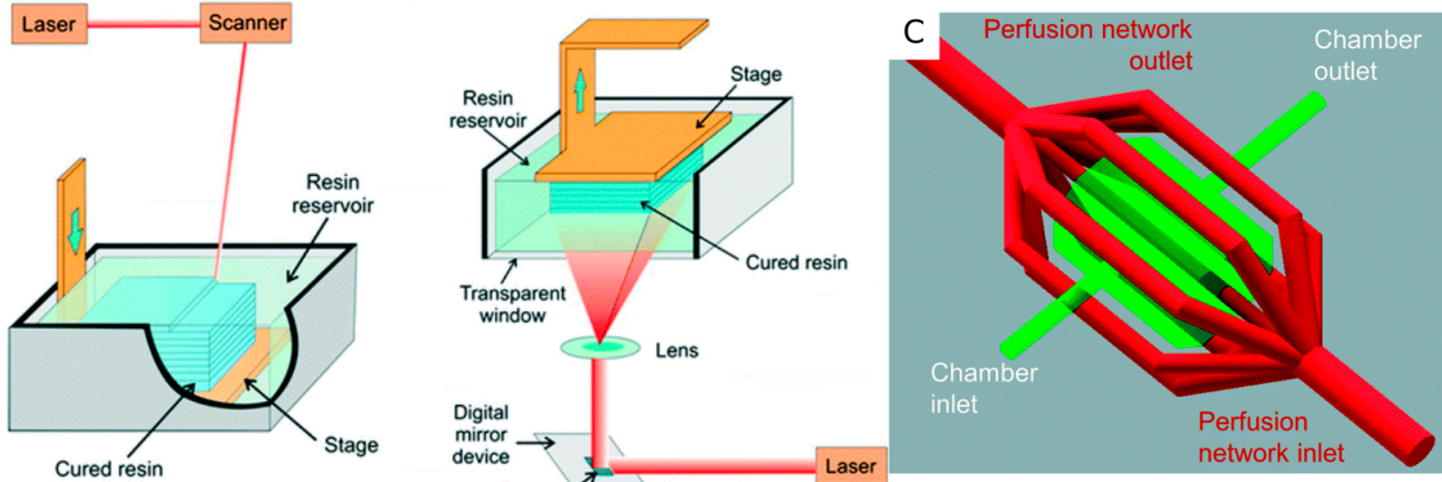

D
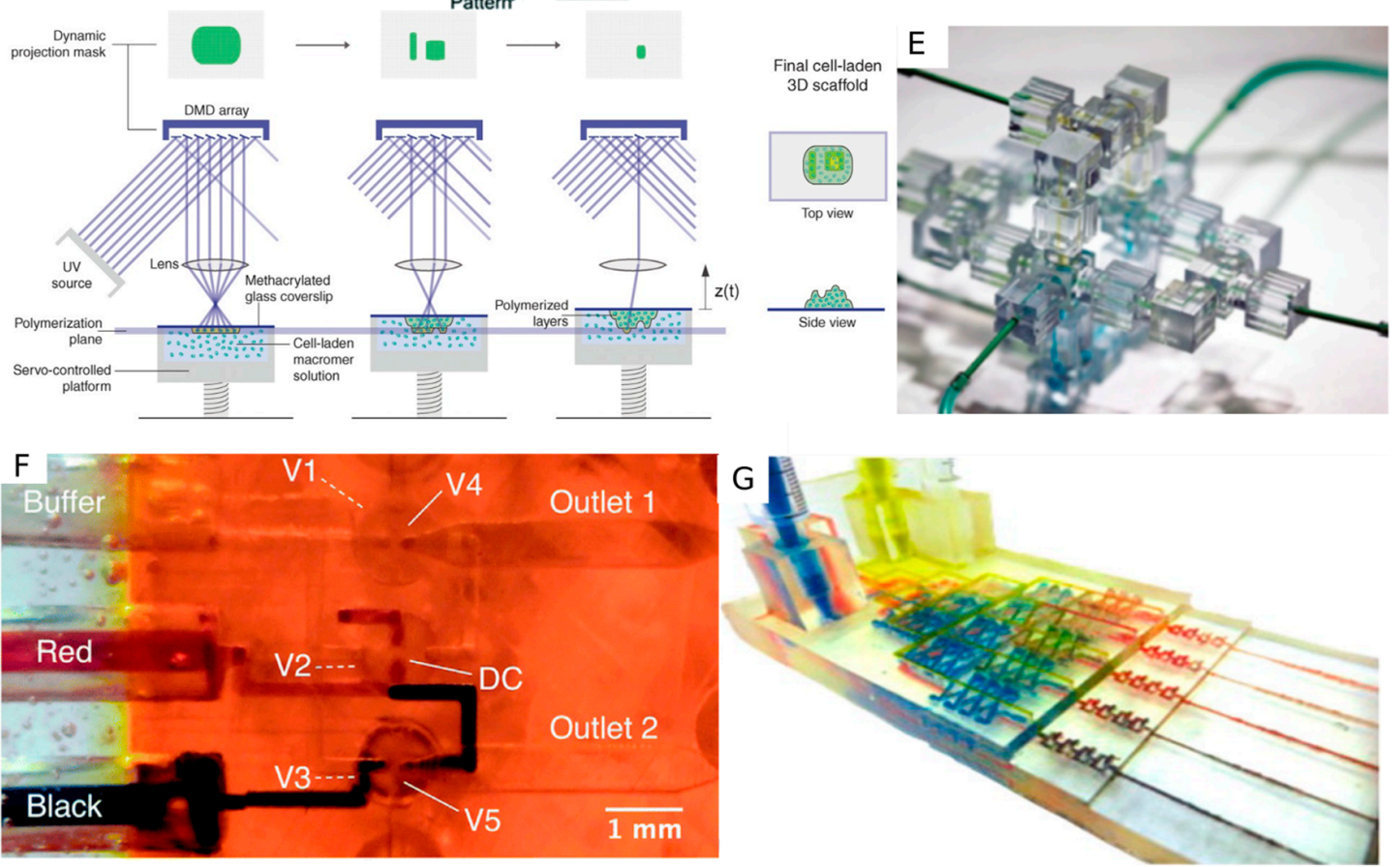

Figure 5. (A) Free surface stereolithography that cures resin at the surface of the resin. (B) Bat configuration, also known as vat stereolithography curing through a transparent surface. (C) Microfluidic perfusion network that is permeable using high weight PEGDA resin. (D) Continuous curing of gelatin-methacrylic resin to encapsulate cells at three different time progressions. (E) Configurable microfluidic elements made by stereolithography elements can be reassembled to meet the microfluidic needs of the system. (F) Microfluidic with pumping and valving made by stereolithography using PEGDA and Sudan I absorber. (G) Microfluidic gradient generator made by stereolithography [42,49-53].

A novel SL process shown by the DeSimone group [54] utilized continuous liquid interface production (CLIP) to increase the speed of SL. The process uses an oxygen-permeable surface to inhibit polymerization on the surface of the vat. The material that polymerizes above the surface is then continuously pulled out of the vat in a layer-less process, eliminating the need for a pull-off step. A relatively new process, Carbon 3D, has been one of the few to build commercial instruments with this process.

For stereolithography to become usable in microfluidics, it is often necessary for the resins to be biocompatible. There has been considerable effort placed into the development of biocompatible resins. There have been some resins used in both MJM and SL printers that are classified as class VI or "medical 
grade", such as Somos Watershed 11122 XC (DSM, Netherlands). Research has been done with custom biocompatible resins, including the use of hydrogel based resins with published formulas and methods. Hydrogels that have been researched for use in microfluidics include polyethylene-glycol-diacrylate (PEG-DA) [49], gelatin methacrylate [51,55], and oligolac [56]. Zhang et al. have shown a way to encapsulate print in a perfusion network for cell culture analysis (Figure 5C) [50]. It should be noted that even though the resins are medical grade, the cytotoxicity should be evaluated on an application level analysis. As shown in Macdonald et al. [57] the use of these class VI resins were not usable for zebrafish embryos (though, as noted, the sensitivity to toxicity in zebrafish embryos is much higher than in humans).

There have been many proof-of-concept demonstrations with SL prints in microfluidics, including micromixers [58], cell separation chips [59], gradient generators (Figure 5G) [60], and micro-needles [61]. An approach to producing 3D printed microfluidic components is shown by Bhargava et al. [52] where the components can be assembled in unique ways (Figure 5E). SL has been demonstrated as a fabrication method for cell studies, as shown by Soman et al. [51], who used a continuous printing process to fabricate GelMa structures to encapsulate cells in a glass coverslip. The volume under the glass coverslip was filled with the GelMa resin, and it was synchronized with a moving platform and changing images to cure a structure that encapsulated the cells between the cover-slip and structure (Figure 5D). A multicellular device was fabricated by Ye Ong et al. [62] for the study of spheroid cultures. The device was fabricated using both SL and Polyjet printing using commercial printers. Wettability control was shown by Credi et al. [63] with the use of perfluoropolyethers (PFPE) in an SL process using Flourolink MD700, a highly hydrophobic material. Textured surfaces were also generated with a high oil resistance using a PFPE monomer-based resin. Currently, the best resolution limit of SL process for microfluidic devices has been achieved by Nordin's group in creating $18 \times$ $20 \mu \mathrm{m}$ channels with high repeatability [64], as well as being able to produce active structures such as pumps and valves (Figure 5F). The ability to integrate greater functionality of SL 3D printed devices have been demonstrated by Folch's group, who generated implanted membranes by switching the vat and using a higher molecular weight PEGDA resin as a porous membrane [65]. Though SL can achieve high resolutions, using multiple materials is difficult compared to processes such as MJM and FDM.

\subsection{Multi Jet Modeling}

Multi Jet Modeling (MJM), known commercially as Polyjet by Stratus, is another 3D printing technology with a potential for application in microfluidics. The process employs a photosensitive resin that is similar to SL. The resin is ejected as a droplet from an inkjet printhead onto the previous layer. It is then cured by a light source attached to the traveling printhead. This process is able to print with high accuracy [66], while utilizing different materials in the same build [67]. Spence et al. fabricated a reusable, high throughput, 3D printed fluidic device using the 3DP-LR printer. They used the device for drug transport and cell viability studies to demonstrate the advantages of the 3D printed device [68]. Candler et al. fabricated the first multi-material 3D printed microfluidic device by printing a flexible polymer gasket connected to rigid clamps [69]. They pressure tested their device by increasing the pressure load, and also its durability at a constant pressure. The use of multi-material printing of MJM has also been demonstrated to make microfluidic valves that are crucial for active microfluidic control Figure 6C [70]. Hwang et al. used this method to fabricate a non-planar PDMS microfluidic channel using photocurable polymer molds [71]. Boutelle et al. used a 3D printed microfluidic device to monitor real-time subcutaneous glucose and lactate levels in cyclists [72]. They successfully integrated FDA-approved clinical microdialysis probes and needle-type biosensors into the device. Printing microfluidic devices with sacrificial material has also been done; however, a material that can be reliably cleared from the channel is not easily achieved [39]. To help with this challenge, a soluble support, named SUP706, has been recently released by Stratasys [42]. Sochol et al. developed nonplanar microfluidic circuitry components with MJM using a sacrificial wax resin during the print Figure $6 \mathrm{~B}$. The wax was removed from the device by submerging it in an $80^{\circ} \mathrm{C}$ 
mineral oil bath, and then flowing the hot mineral oil and compressed air through the channels [73]. The issue with this technology is that the MJM machines tend to be expensive, and most resins are proprietary [42]. Also, MJM can have difficulty producing features in the submillimeter range [62].

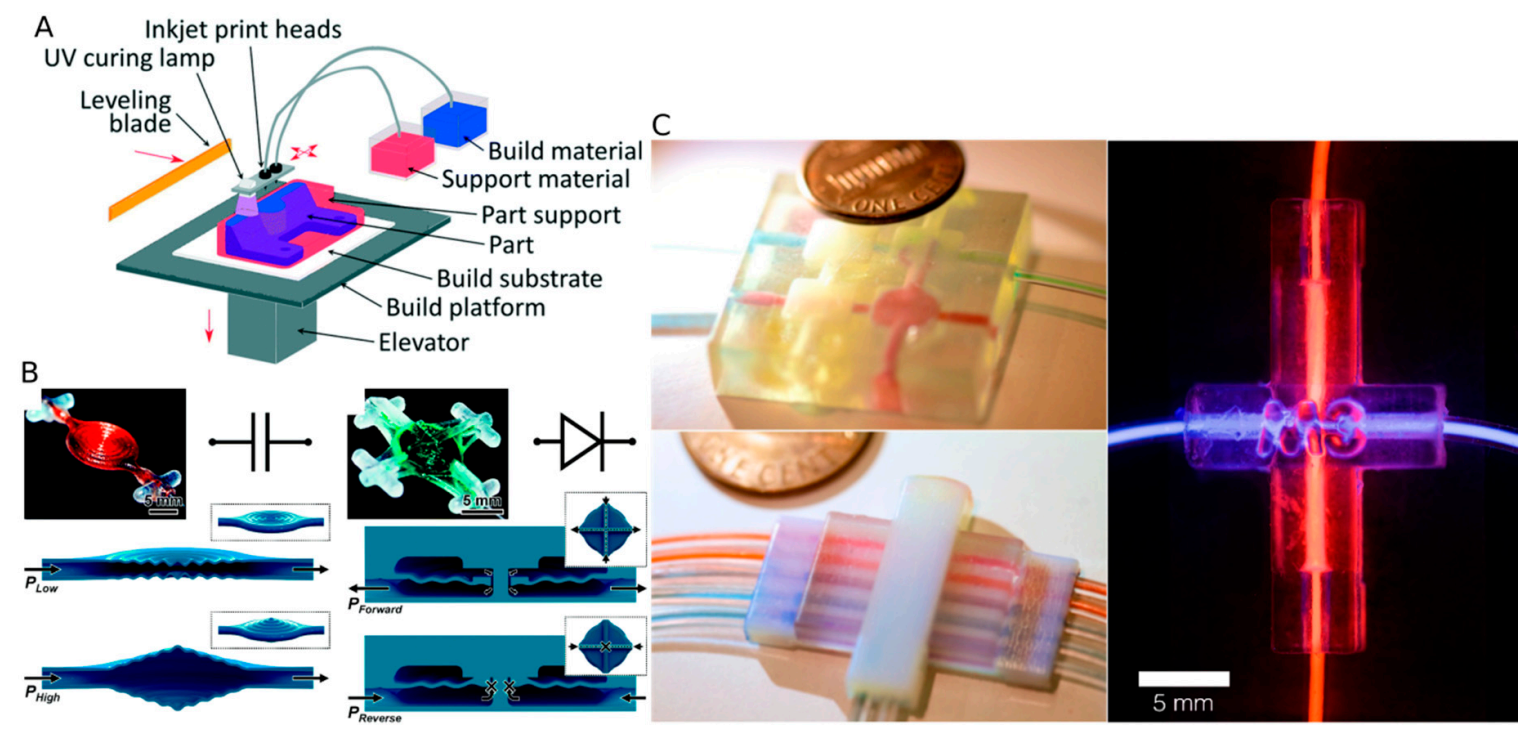

Figure 6. (A) Multi-jet modeling (MJM) apparatus with a traveling inkjet printhead and a UV curing lamp. (B) 3D printed circuit components made by MJM using a sacrificial material. (C) Multimaterial valve made by using MJM with integrated elastic membrane [42,70,73].

\subsection{Two-Photon Polymerization}

While the techniques mentioned above are only limited to microscale resolutions, a 3D writing technique has been developed that can produce nanometer sized features: direct femtosecond laser writing (DLW) by two-photon polymerization (2PP). This process is unique in its ability to write structures by curing arbitrary spots within the material, but the required equipment tends to be very expensive. The other optical 3D printing processes can be classified as single photon polymerization, in which a photo-initiator only needs to absorb a single photon for a photochemical reaction. In the case of multi-photon polymerization, a near-infrared laser is focused to where a photo-initiator species either absorb two photons simultaneously or absorbs a single photon to transition to an intermediate state and then a second photon is absorbed. The two-photon requirement also typically requires two light sources, and the overlapped light regions are where the reactions occur. The materials used are typically photopolymers, though the process has been able to produce polymerization, even when no photo-initiator is present in the formula. The high nonlinearity of the optics and polymerization allows for the sub-100 nm features. The light is typically only applied in femtosecond bursts that can only be achieved with a Ti:sapphire laser or other fs-lasers [74]. DLW requires the movement of a stage with piezoelectric actuators and galvano-mirror scanners. Piezoelectric actuators typically have a position accuracy as small as $\sim 1 \mathrm{~nm}$. Due to the resolution of this manufacturing process and its limits, the speed at which structures are built is relatively slow.

DLW enables new ways to manufacture microfluidic components in assembled channels. Koji Sugioka et al. [75] has shown the ability to manufacture a microfluidic micromixer inside an assembled channel using 2PP (Figure 7C). Dong Wu et al. [76] called 2PP a ship-in-a-bottle technique creating parallel cell counters, and microlens arrays manufactured inside a glass substrate (Figure 7D). Two-photon polymerization is a relatively new and powerful additive manufacturing technique that is still relatively new, and that can produce rapid nanoscale features. 
A
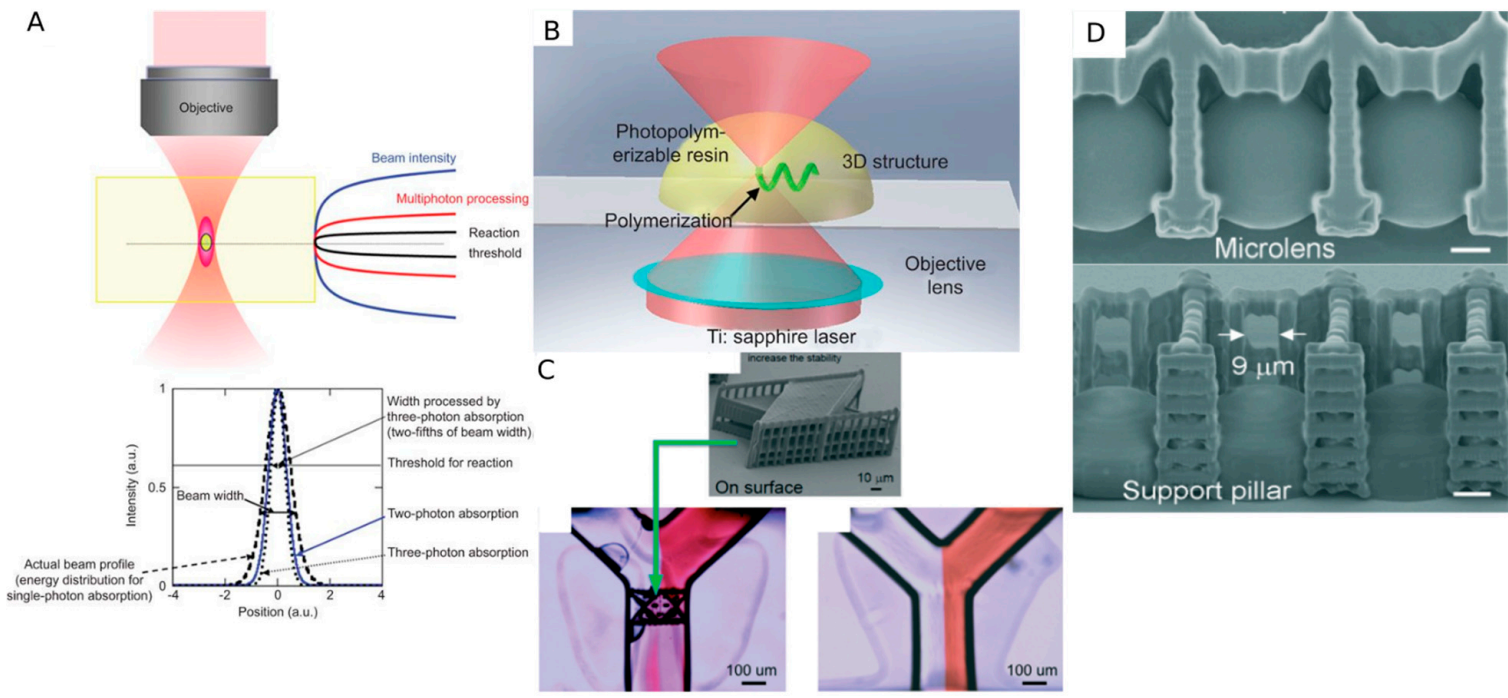

Figure 7. (A) Two-photon polymerization is able to cure sub-micron "points" due to the non-linear intensity, and polymerization. (B) Two-photon polymerization helix and 3D writing ability. (C) Micromixer fabricated inside a microfluidic channel with (left) and without (right). (D) Cell counter array with the use of a microlens (top) and supporting separator (bottom) [75-77].

\section{Nanofabrication}

Nanostructures have been employed in many fields due to their unique properties, and they have found uses in microfluidics as well. As such, several fabrication techniques have been developed to generate 2D and 3D nanostructures. Nanofabrication techniques can typically be categorized into two groups: top-down methods and bottom-up methods.

Top-down techniques allow for good control of the size and distribution of features, and they commonly involve some form of photolithography. Photolithography involves the generation an outline of the desired micro/nanoscale device on a partially transparent photomask. After generation, an image of this mask is projected onto a substrate wafer that has been coated in a photosensitive polymer or "resist". This enables the transfer of the generated pattern from the photomask to the substrate wafer. In standard photolithographic methods, an ultraviolet light source ranging from 250 to $435 \mathrm{~nm}$ is employed to create the image on the photosensitive material [78]. While these sources can reliably produce micron sized features, the effects of diffraction prevent the resolution of sub-250 nm features onto the substrate. Due to diffraction, the limits of resolution of standard lithographic processes is typically on the order of the wavelength of light being used to create the image [78,79]. Several techniques such as extreme ultraviolet lithography, electron beam lithography, and nanoimprint lithography have been developed to circumvent these limits. Lithographic approaches to reduce the feature size typically involve the reduction of the wavelength of the light source used to generate images onto the substrate. Subsequent deposition and etching steps follow until the device is complete.

While advanced photolithography techniques can provide sub-250 nm structures, the procedures required to produce such structures are highly serialized and slow. Pattern transfer via lithographic methods is also often subject to defects due to defects on the mask, contact with the mask, and diffraction of light. Finally, use of lithography techniques is expensive since these techniques often involve extensive use of clean room equipment. There has recently been a desire from many different sectors of industry for the rapid fabrication of periodic and ordered nanostructures. Bottom-up nanofabrication techniques have been proposed as an alternative to circumvent the shortcomings of photolithography. Bottom-up nanofabrication techniques involve the formation of nanoscale structures through the self-arrangement of atomic and molecular building blocks. This molecular nature allows for highly repeatable, periodic structures. 
In this review, three nanoscale lithographic methods (Extreme Ultraviolet, Electron Beam, and Nanoimprint lithography), as well as one non-lithographic (Anodic Aluminum Oxidation), are examined in relation to microfluidic fabrication. The working principles, applications to microfluidics, and prospects for commercialization for each technique are evaluated.

\subsection{Extreme Ultraviolet Lithography}

Extreme ultraviolet lithography (EUV) is an optical lithographic process like standard lithography described above. However, EUV uses $13 \mathrm{~nm}$ light for substrate exposure [80]. To generate these small wavelengths of light, a laser is used to illuminate a plasma, such as a xenon plasma. The plasma, in turn, emits the EUV light. This light is concentrated using a system of mirrors which have up to $70 \%$ reflectivity of light. The EUV light is then shone from a reflective mask into a system of reducing mirrors. These mirrors reduce the spot size of the light beam into the desired double-digit nanometer range. This light is then shone onto a special photosensitive resist, after which typical developing and etching protocols can be followed [81].

While reports of fabrication of microfluidic devices with the use of EUV are rare, extreme ultraviolet lithography can be used for the fabrication of nanopillars to study cells. Both the use of nanopillars to study cells in microfluidic devices and the use of EUV to fabricate pillars have been reported previously $[82,83]$. Additionally, EUV has been found to be advantageous over other standard lithographic techniques for the creation of microfluidic and nanofluidic channels with varying geometries when it is combined with gray-scale lithography [84].

Otherwise, it seems that EUV applications in nanofluidics have been limited, but are likely to develop as research moves to smaller length scales. However, due to its high cost, it is unlikely that EUV will see extensive applications in microfluidics.

Commercially, however, extreme ultraviolet lithography has found its niche in the semiconductor industry. Practical EUV use has been reported in the creation of integrated circuit chips. Recently, IBM reported the creation of 5 and $7 \mathrm{~nm}$ transistor nodes using extreme ultraviolet lithography. The $5 \mathrm{~nm}$ chip offers a 40 percent increase in performance, while using 75 percent less power than the $10 \mathrm{~nm}$ chips that are currently on the market. While the $5 \mathrm{~nm}$ chips are still in the developmental stage, the $7 \mathrm{~nm}$ chips will be available on the market in 2018 [85]. Companies like IBM and Intel will continue to provide funding for the development of EUV as they view it as the best prospective technology to reduce the size of transistor nodes [86].

\subsection{Electron Beam Lithography}

Electron beam lithography (EBL) is a lithographic method derived from the development of the scanning electron microscope (SEM) [87]. Like other lithographic processes, its focus is the transfer of patterns onto a structure using a reactive resist. However, unlike other lithographic methods, it uses a focused electron beam, rather than light, to expose an electron reactive resist. When the high energy electron beam interacts with the resist coating, either the solubility of the resist is increased, or a crosslinking of polymers occur. EBL is a mask-less lithographic technique, since the electron beam that is used to expose the surface is rastered over the surface to generate the patterns that are desired. This makes it advantageous over masked techniques, since defects due to masking are no longer present. However, the rastering process of EBL makes it a fairly low throughput process [88]. Electron beam lithography is advantageous over conventional lithography because of the extremely small feature size generation possible. Since EBL does not involve the typical optical elements used in standard photolithography, it is able to overcome the diffraction limited minimum feature size of standard photolithography, and it has been able to generate feature sizes less than $10 \mathrm{~nm}$ [78].

While rare, the use of electron beam lithography for the manufacturing of microfluidic structures has been proposed [89]. Electron beam lithography can be used in micro- and nanofluidics for the creation of nanochannels. It is also an ideal technique for use with tissue engineering and biosensors [88]. Moolman et al. reported the fabrication of a microfluidic chip, with nanochannels 
ranging from 300 to $800 \mathrm{~nm}$ in width and $1.2 \mu \mathrm{m}$ in depth, with the use of EBL. This device was used to study the growth of several submicron species of bacteria over many generations. Channels created on a silicon wafer were used to create a stiff negative PDMS master mold, which in turn was used to create several softer PDMS channels. The final PDMS channels were bonded to a glass cover-slip. Figure 8 summarizes the fabrication process for this device. Moolman proved the functionality of the fabricated device, by growing both Escherichia coli and Lactococcus lactis in the fabricated devices for several generations. The use of EBL in this work provided Moolman et al. greater control of the size and shape of structures in their microfluidics device when compared to a similar device that was constructed using conventional lithographic techniques [90,91].
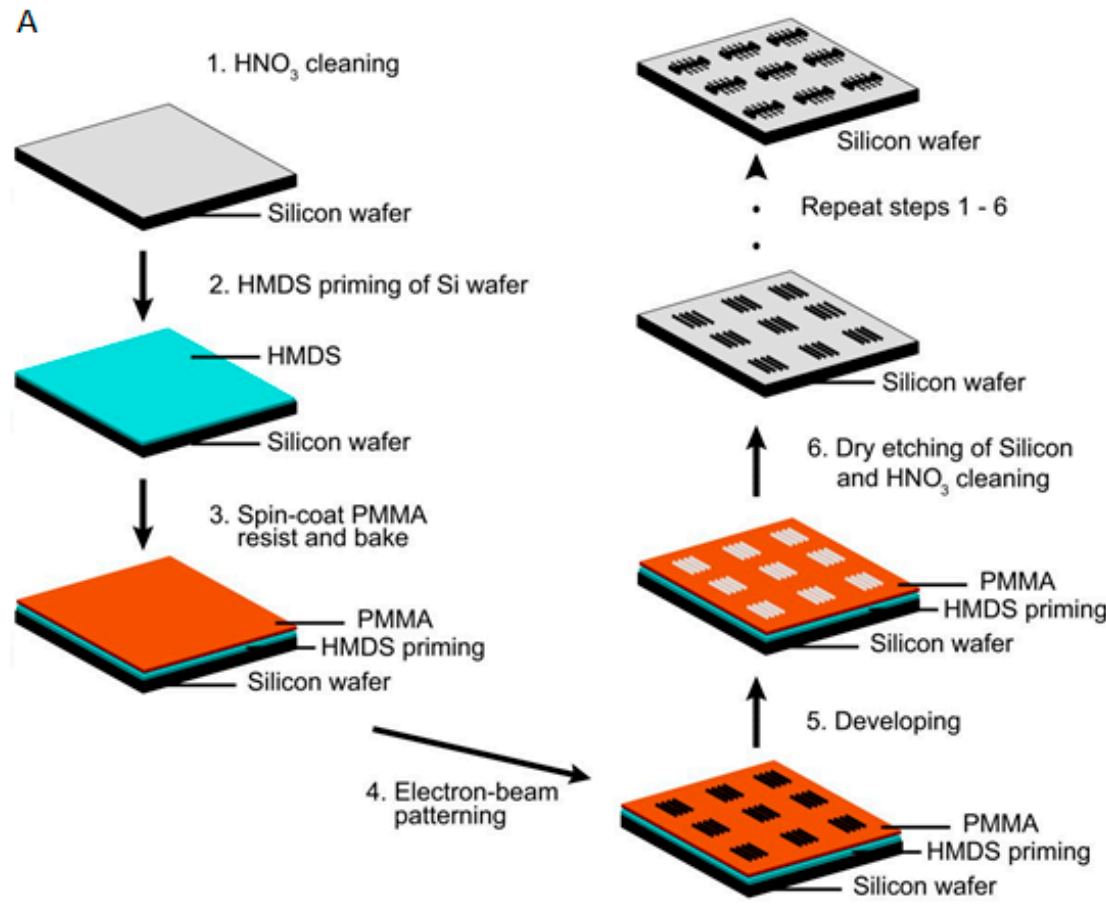

B

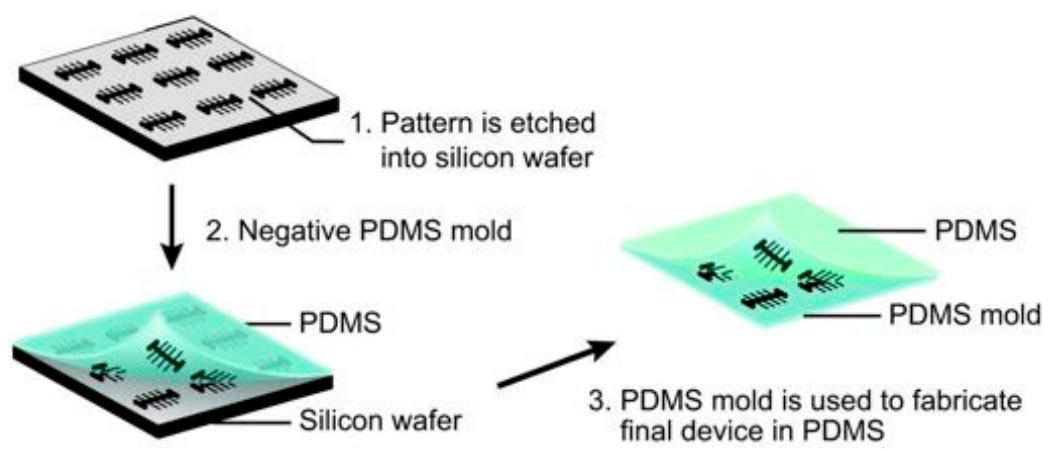

Figure 8. (A) The electron beam lithography EBL process steps used to create the silicon mold. (B) Fabrication of the polydimethylsiloxane (PDMS) master mold and subsequent soft PDMS molds [90].

Given that EBL originates from the modification of already existing technologies, its adoption into spaces where SEMs are already present should not be too laborious. As such, commercial production of electron beam lithography tools is ongoing, and companies are actively developing new and improved EBL systems, though they remain expensive and slow [92]. However, due to its highly serial nature, EBL will likely not be readily adopted in fields requiring the high throughput creation of devices such as microfluidics. 


\subsection{Nanoimprint Lithography}

While E-beam and EUV lithography do satisfy the need for sub-20 nm nanostructures, they are both fairly expensive and low throughput processes [93]. There is, therefore, a desire for high throughput, low-cost lithographic processes that can easily generate sub-20 nm structures in high-throughput and at a reasonable cost. Nanoimprint lithography (NIL) is such a process. Like stamping, nanoimprint lithography is primarily a mechanical process in which a prefabricated mold is pressed into a resist material. After the mold is pressed into the material, further hardening of the resist can be achieved using either thermal, chemical, or optical methods such as UV curing. After sufficient deformation of the resist material has been achieved, the mold is removed from the resist surface and further development steps can take place [94].

As it is a low cost, high throughput technology, NIL has been applied for the fabrication of many different microfluidic devices. Isobe et al. built a microfluidic system which consisted of micrometer channels as well as an array of parallel $500 \mathrm{~nm}$ wide and 1-2 $\mu \mathrm{m}$ tall channels for delivering solutions in microfluidic bioassays. To achieve this, a combination of UV-assisted thermal NIL, as well as standard UV lithography, was used. SU-8 was spin-coated on a silicon wafer and pre-exposed to initiate crosslinking in the SU-8. Following this, thermal nanoimprint lithography was performed to generate the nanochannel array. After post exposure, an additional layer of SU-8 was spun onto the wafer and processed using standard UV lithographic processes. The SU-8 structures generated by these processes were used as a mold to form channels in PDMS [93]. Figure 9 provides a schematic of this device.

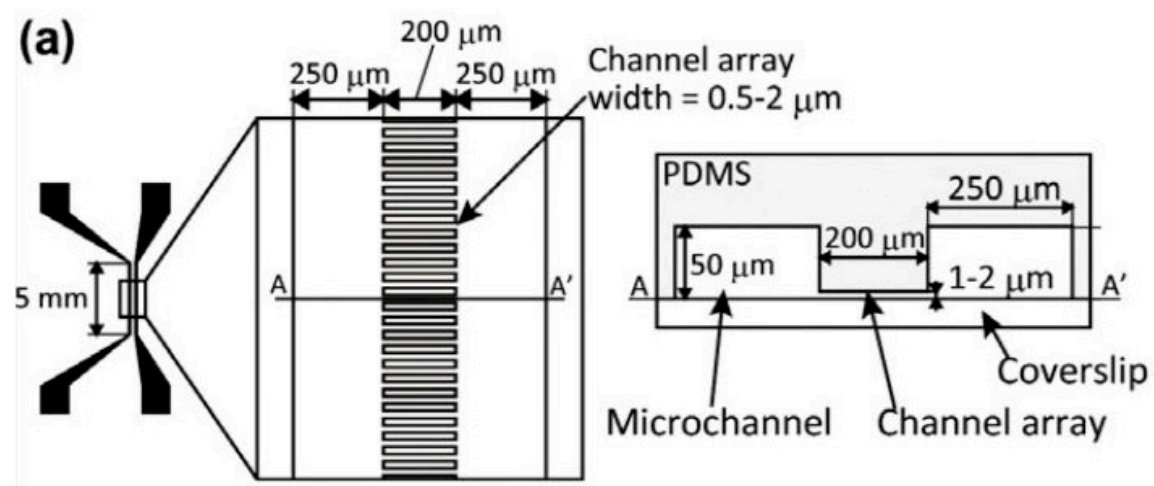

(b)

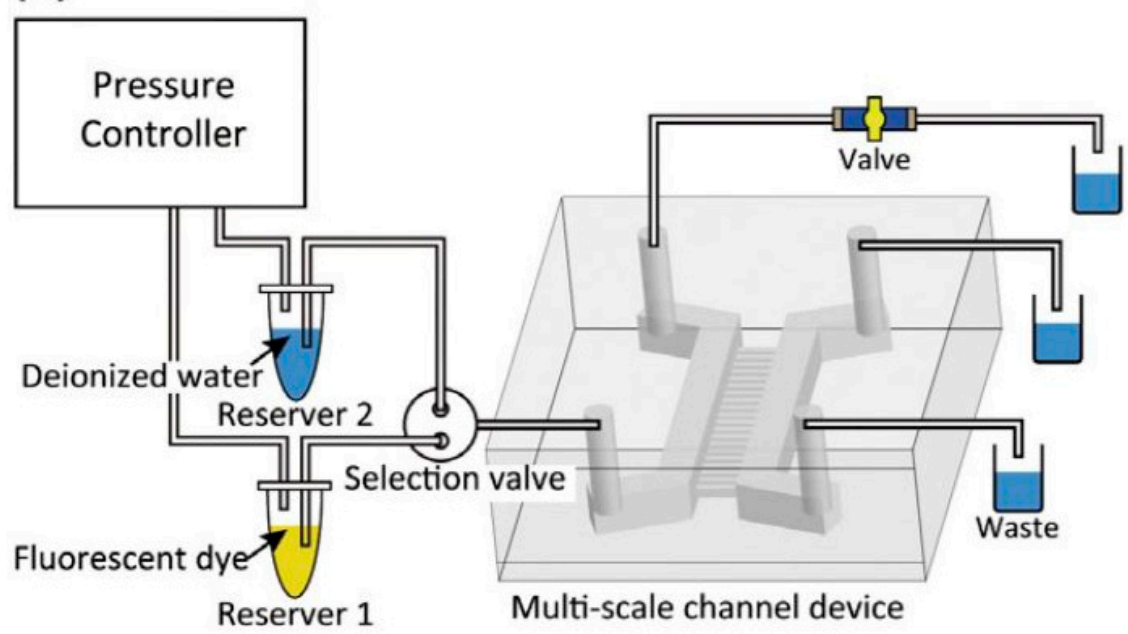

Figure 9. (a) Dimension of the perfusion device. (b) Schematic of the device as controlled by a pressure driven flow [93]. 
Nanoimprint lithography displays promise for wide commercialization. NIL is both a high throughput and a low-cost process. These features are very desirable to the semiconductor and microfluidics industry. Due to its advantages over extreme UV and E beam lithographies, high profile companies like Canon have begun to make large investments in its advancement [95]. Advancements in NIL, such as roll-to-roll NIL, promise to improve the throughput of NIL even further, though at the cost of minimum feature size [96]. Recently, roll-to-roll NIL was used to continuously imprint a polyethersulfone ultrafiltration membrane onto a substrate [97]. This illustrates NIL's application in the fabrication of commercial devices, both in microfluidics and in the semiconductor industry.

\subsection{Anodic Aluminum Oxidation}

The use of oxidized aluminum to prevent wear and corrosion has been commonplace for a long time [98], but it has been found that these structures are also useful for membranes and nanofluidics. Anodic aluminum oxidation (AAO) occurs when aluminum is placed in an acidic electrolyte and current is passed through the solution with the aluminum sheet placed on the anode, resulting in the formation of close-packed, uniform, porous hexagonal cells. These cells can range in diameter from $4 \mathrm{~nm}$ to $200 \mathrm{~nm}$, and can grow perpendicularly to a height determined by the electrochemical conditions. Techniques for the fabrication of highly ordered metal nanohole arrays, such as gold nanoholes, based on AAO have developed, and they are reported by Masuda and Fukuda [99]. To achieve these nanoholes, first, a porous aluminum oxide layer is developed on an aluminum substrate at appropriated anodization voltages. Next, a thin metal layer is deposited on top of the porous aluminum with the use of physical or chemical vapor deposition techniques. Following this, a resist is used to fill up the porous alumina and developed. This step creates a negative cylindrical resist mold that may be used to create further nanoholes with methods varying from soft lithography to metal plating [100].

Current research on the fabrication of nanostructures using AAO involves the use of hierarchically branched AAO templated to fabricate asymmetric nanopillars [101]. While the reported use of AAO for microfluidics is limited, potential applications still exist. The use of AAO for the formation of ultrathin membranes has been widely reported [102]. Recently, Sharma and Gale reported the integration of an aluminum oxide membrane (AOM) into a microfluidic device, and its use for the electrochemical quantification of DNA $[103,104]$. Given that PDMS, a primary polymer of choice for microfluidics, does not bond well with AAO membranes, the aluminum oxide membrane in this case had to be embedded in double-sided tape. Figure 10 shows a schematic of the manufactured device. This device was able to successfully capture genomic DNA due to the charge on the AOM. Additionally, the use of AAO membranes has been reported for the development of highly organized arrays for use with microfluidics. Chen at al. reported the use of an AAO membrane to organize and dry an Ag nanodot array onto the surface of a quartz slide. This slide was then sealed within a microfluidic channel made of PDMS, and the device was used to perform surface-enhanced Raman spectroscopy [105].

The anodic oxidation of aluminum stands a good chance of becoming a standard process in microfluidics. Given that commercial AAO has existed for a long time in other industries, the equipment with which AAO can be performed is readily available. It is also a rapid technique in comparison to the fabrication of nanopillars/pore with methods like extreme ultraviolet lithography. AAO membranes are already made by companies like GE Whatman. The potential for AAO to generate complex nanopillars arrays that can be used in cell biology and diagnostics make it a worthwhile nanofabrication technique that should garner more attention than it currently receives. 
(A)

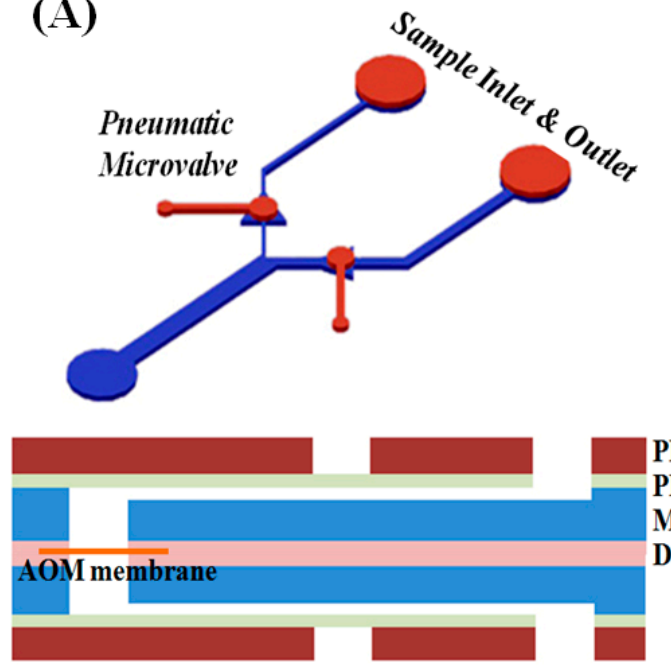

(B)

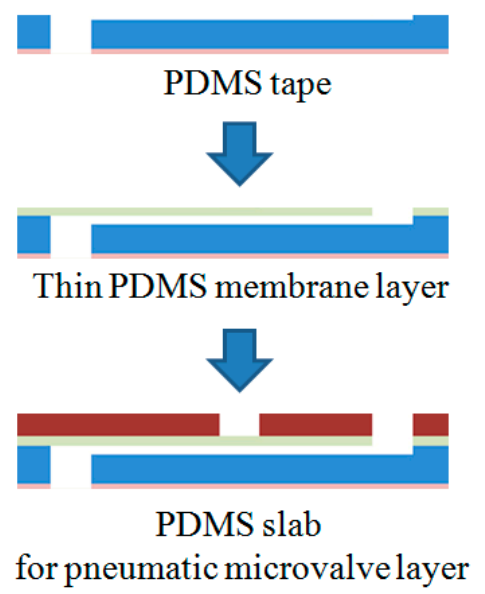

Figure 10. Schematic of the proposed microfluidic device containing a PDMS-double-sided tape-AOM membrane sandwich (A) Channel layout of the microfluidic system. (B) Cross section view of the fabrication process [104].

\section{Conclusions}

Newly developed manufacturing techniques that go beyond soft lithography have helped to bring microfluidics into regular use by academia, industry, and the public. The techniques presented in this review help provide insight into the current and upcoming manufacturing processes that will important in microfluidics.

Molding has been the fundamental process used in academic microfluidics labs for many years. The approach of replica molding using PDMS continues to provide a valuable platform for research, prototyping, and custom biomedical microfluidics, while injection molding and hot embossing are popular in producing commercial microfluidic devices. The recent advances in replica molding appear to be partially focused on providing improved tools for 3D cell culturing. Research in injection molding and hot embossing aims to address limitations in mold cost, as well as further improve the functionality of existing methods and materials.

The use of laminates, undoubtedly, has a long-term future in microfluidics, and it is especially practical in moving microfluidics toward commercialization. Perhaps we will see 3D printed devices encroach on space traditionally claimed by laminates, but laminates perform far better in scaled-up manufacturing and enable the incorporation of multiple materials and components. These benefits across multiple materials and with an increasingly broad range of materials will become even more apparent, especially when recognizing recent advancements in bonding and alignment methods.

The use of nanoscale structures in microfluidics is widespread for the study of bacteria growth, cell adhesion, detection of biomarkers, and the study of diffusion. For a nanofabrication method to be successfully adopted for use in microfluidics, it is required that the process be low cost, high throughput, generate small feature size, and reproducible. While many of the methods mentioned can reproducibly create sub-20 nm structures, fabrication methods such as electron beam lithography and extreme ultraviolet lithography currently have their use in microfluidics is limited by both their cost and serial processing. High throughput methods like nanoimprint lithography and anodic aluminum oxidation, however, are likely to generate more use in microfluidics. Both methods meet the requirements for rapid prototyping, have seen some commercial success, and can be performed with simple equipment.

There have been some barriers to commercializing microfluidic devices that traditional fabrication methods have failed to address, but that may be solved by 3D printing. Specifically, there are three barriers that need to be overcome: non-standard user interfaces, complex control systems, and the 
fact that liquid polymer (i.e., PDMS) molding is not easily commercialized due to speed and cost concerns. In many instances, 3D printing seems to be the solution to these problems. It is inexpensive for making prototypes, and the technologies are getting more cost-effective and faster each year. A variety of materials have been developed to meet the need of microfluidics, with properties such as being transparent, non-fluorescent and biocompatible. However, 3D printing has not been able to produce the same resolutions as PDMS manufacturing, in its current state. There have been great improvements in 3D printing of finer channels in recent years using SL, as well as 3D printing using two-photon manufacturing to achieve submicron resolution., though two-photon polymerization does tend to be expensive and slow. Biocompatibility does need to be addressed with processes such as SL and MJM, though hydrogels such as PEGDA have shown promise in this area. As 3D printing improves, advances in 3D printing with different materials and resolutions have the potential to develop integrated microfluidics devices in a single step process with multi-material capabilities and integrated circuits [106] 3D printing has had great improvements due to its recent popularity, and it has the potential to have a lasting impact on the field. There is a high probability that as 3D printing improves, it will replace nearly all the other methods of microfluidic device manufacturing in research and a good probability that 3D printing will become the primary commercial manufacturing methods due to its straightforward scale-up and custom device manufacturing potential. Overall, multiple methods for manufacturing microfluidic and nanofluidic devices exist, and rapid development of these methods is allowing for new and unique applications in the medical, biological, and chemical areas.

Author Contributions: A.R.J. researched and prepared the section on laminates; C.J.L. researched and prepared the section on molding; B.L.G. and H.M. researched and prepared the section on 3D printing; U.C.N. researched and prepared the section on nanofabrication; S.K.K. supervised overall flow, editing, and clarity; B.K.G. directed overall research topics and objectives, reviewed the document carefully, and contributed text in several areas. All authors contributed equally to this work.

Funding: This research received no external funding.

Acknowledgments: A.J. acknowledges support from the National Science Foundation Graduate Research Fellowship under Grant No. 1747505.

Conflicts of Interest: The authors declare no conflicts of interest.

\section{References}

1. Hansen, C.L.; Skordalakes, E.; Berger, J.M.; Quake, S.R. A robust and scalable microfluidic metering method that allows protein crystal growth by free interface diffusion. Proc. Natl. Acad. Sci. USA 2002, 99, 16531-16536. [CrossRef] [PubMed]

2. Takayama, S.; Ostuni, E.; LeDuc, P.; Naruse, K.; Ingber, D.E.; Whitesides, G.M. Subcellular positioning of small molecules. Nature 2001, 411, 1016. [CrossRef] [PubMed]

3. Son, J.; Samuel, R.; Gale, B.K.; Carrell, D.T.; Hotaling, J.M. Separation of sperm cells from samples containing high concentrations of white blood cells using a spiral channel. Biomicrofluidics 2017, 11, 054106. [CrossRef] [PubMed]

4. Jafek, A.R.; Harbertson, S.; Brady, H.; Samuel, R.; Gale, B.K. Instrumentation for xPCR Incorporating qPCR and HRMA. Anal. Chem. 2018, 90, 7190-7196. [CrossRef] [PubMed]

5. Bange, A.; Halsall, H.B.; Heineman, W.R. Microfluidic immunosensor systems. Biosens. Bioelectron. 2005, 20, 2488-2503. [CrossRef] [PubMed]

6. Safdar, M.; Jänis, J.; Sánchez, S. Microfluidic fuel cells for energy generation. Lab Chip 2016, 16, $2754-2758$. [CrossRef] [PubMed]

7. Guo, M.T.; Rotem, A.; Heyman, J.A.; Weitz, D.A. Droplet microfluidics for high-throughput biological assays. Lab Chip 2012, 12, 2146. [CrossRef] [PubMed]

8. Xia, Y.; Whitesides, G.M. SOFT LITHOGRAPHY. Annu. Rev. Mater. Sci. 1998, 28, 153-184. [CrossRef]

9. McDonald, J.C.; Duffy, D.C.; Anderson, J.R.; Chiu, D.T.; Wu, H.; Schueller, O.J.; Whitesides, G.M. Fabrication of microfluidic systems in poly(dimethylsiloxane). Electrophoresis 2000, 21, 27-40. [CrossRef]

10. Kim, P.; Kwon, K.W.; Park, M.C.; Lee, S.H.; Kim, S.M. Soft Lithography for Microfluidics: A Review. Biochip J. 2008, 2, 1-11. 
11. Qin, D.; Xia, Y.; Whitesides, G.M. Soft lithography for micro- and nanoscale patterning. Nat. Protoc. 2010, 5, 491-502. [CrossRef] [PubMed]

12. Faustino, V.; Catarino, S.O.; Lima, R.; Minas, G. Biomedical microfluidic devices by using low-cost fabrication techniques: A review. J. Biomech. 2016, 49, 2280-2292. [CrossRef] [PubMed]

13. Xia, Y.; Si, J.; Li, Z. Fabrication techniques for microfluidic paper-based analytical devices and their applications for biological testing: A review. Biosens. Bioelectron. 2016, 77, 774-789. [CrossRef] [PubMed]

14. Walsh, D.I.; Kong, D.S.; Murthy, S.K.; Carr, P.A. Enabling Microfluidics: from Clean Rooms to Makerspaces. Trends Biotechnol. 2017, 35, 383-392. [CrossRef] [PubMed]

15. Ontiveros, F.; Mcdowell, J.R. Ultra-Thin Microfluidic Devices Built via Thermal Lamination; Biology Faculty Publications, Paper 28; St. John Fisher College: Rochester, NY, USA, 2016.

16. Nath, P.; Fung, D.; Kunde, Y.A.; Zeytun, A.; Branch, B.; Goddard, G. Rapid prototyping of robust and versatile microfluidic components using adhesive transfer tapes. Lab Chip 2010, 10, 2286. [CrossRef] [PubMed]

17. Kinahan, D.J.; Julius, L.A. N.; Schoen, C.; Dreo, T.; Ducrée, J. Automated Dna Purification and Multiplexed Lamp Assay Preparation on a Centrifugal Microfluidic " Lab -on-a- Disc " Platform. In Proceedings of the 2018 IEEE Micro Electro Mechanical Systems (MEMS) Belfast, UK, 21-25 January 2018; pp. 1134-1137.

18. Mahmud, M.; Blondeel, E.; Kaddoura, M.; MacDonald, B. Features in Microfluidic Paper-Based Devices Made by Laser Cutting: How Small Can They Be? Micromachines 2018, 9, 220. [CrossRef]

19. Serra, M.; Pereiro, I.; Yamada, A.; Viovy, J.-L.; Descroix, S.; Ferraro, D. A simple and low-cost chip bonding solution for high pressure, high temperature and biological applications. Lab Chip 2017, 17, 629-634. [CrossRef] [PubMed]

20. Focke, M.; Kosse, D.; Müller, C.; Reinecke, H.; Zengerle, R.; von Stetten, F. Lab-on-a-Foil: Microfluidics on thin and flexible films. Lab Chip 2010, 10, 1365. [CrossRef] [PubMed]

21. Romanov, V.; McCullough, J.; Gale, B.; Frost, A. Nanoemulsions. Unpublished work, 2018.

22. Martin, P.M.; Matson, D.W.; Bennett, W.D.; Lin, Y.; Hammerstrom, D.J. Laminated plastic microfluidic components for biological and chemical systems. J. Vac. Sci. Technol. A Vac. Surf. Film 1999, 17, 2264-2269. [CrossRef]

23. Weigl, B.H.; Bardell, R.; Schulte, T.; Battrell, F.; Hayenga, J. Design and Rapid Prototyping of Thin-Film Laminate-Based Microfluidic Devices. Circuit Des. 2001, 267-274.

24. Wu, J.; Gu, M. Microfluidic sensing: State of the art fabrication and detection techniques. J. Biomed. Opt. 2011, 16, 080901. [CrossRef] [PubMed]

25. Pinto, V.C.; Sousa, P.J.; Cardoso, V.F.; Minas, G. Optimized SU-8 processing for low-cost microstructures fabrication without cleanroom facilities. Micromachines 2014, 5, 738-755. [CrossRef]

26. Li, Z.; Gu, Y.; Wang, L.; Ge, H.; Wu, W.; Xia, Q.; Yuan, C.; Chen, Y.; Cui, B.; Williams, R.S. Hybrid Nanoimprint-Soft Lithography with Sub-15 nm Resolution 2009. Nano Lett. 2009, 9, 2306-2310. [CrossRef] [PubMed]

27. Yang, Y.; Kulangara, K.; Sia, J.; Wang, L.; Leong, K.W. Engineering of a microfluidic cell culture platform embedded with nanoscale features. Lab Chip 2011, 11, 1638-1646. [CrossRef] [PubMed]

28. Ugolini, G.S.; Visone, R.; Redaelli, A.; Moretti, M.; Rasponi, M. Generating Multicompartmental 3D Biological Constructs Interfaced through Sequential Injections in Microfluidic Devices. Adv. Healthc. Mater. 2017, 6. [CrossRef] [PubMed]

29. Sticker, D.; Rothbauer, M.; Lechner, S.; Hehenberger, M.T.; Ertl, P. Multi-layered, membrane-integrated microfluidics based on replica molding of a thiol-ene epoxy thermoset for organ-on-a-chip applications. Lab Chip 2015, 15, 4542-4554. [CrossRef] [PubMed]

30. Giboz, J.; Copponnex, T.; Mélé, P. Microinjection molding of thermoplastic polymers: A review. J. Micromech. Microeng. 2007, 17. [CrossRef]

31. Wiedemeier, S.; Römer, R.; Wächter, S.; Staps, U.; Kolbe, C.; Gastrock, G. Precision moulding of biomimetic disposable chips for droplet-based applications. Microfluid. Nanofluidics 2017, 21,1-11. [CrossRef]

32. Szydzik, C.; Gavela, A.F.; Herranz, S.; Roccisano, J.; Knoerzer, M.; Thurgood, P.; Khoshmanesh, K.; Mitchell, A.; Lechuga, L.M. An automated optofluidic biosensor platform combining interferometric sensors and injection moulded microfluidics. Lab Chip 2017, 17, 2793-2804. [CrossRef] [PubMed]

33. Vereshchagina, E.; Andreassen, E.; Gaarder, R.; Mielnik, M.M. Synergy of 3D Printing and Injection Molding: A New Prototyping Method for Rapid Design Optimization and Manufacturing of Microfluidic Devices. In Proceedings of the $\mu$ TAS 2017 Conference, Savannah, GA, USA, 22-26 October 2017. 
34. Lin, T.Y.; Do, T.; Kwon, P.; Lillehoj, P.B. 3D printed metal molds for hot embossing plastic microfluidic devices. Lab Chip 2017, 17, 241-247. [CrossRef] [PubMed]

35. Weerakoon-Ratnayake, K.M.; O’Neil, C.E.; Uba, F.I.; Soper, S.A. Thermoplastic nanofluidic devices for biomedical applications. Lab Chip 2017, 17, 362-381. [CrossRef] [PubMed]

36. Heckele, M.; Schomburg, W.K. Review on micro molding of thermoplastic polymers. J. Micromech. Microeng. 2004, 14. [CrossRef]

37. Bocquet, L.; Tabeling, P. Physics and technological aspects of nanofluidics. Lab Chip 2014, 14, 3143-3158. [CrossRef] [PubMed]

38. Debono, M.; Voicu, D.; Pousti, M.; Safdar, M.; Young, R.; Kumacheva, E.; Greener, J. One-step fabrication of microchannels with integrated three dimensional features by hot intrusion embossing. Sensors 2016, 16, 2023. [CrossRef] [PubMed]

39. Au, A.K.; Huynh, W.; Horowitz, L.F.; Folch, A. 3D-Printed Microfluidics. Angew. Chem. Int. Ed. 2016, 55, 3862-3881. [CrossRef] [PubMed]

40. Waheed, S.; Cabot, J.M.; Macdonald, N.P.; Lewis, T.; Guijt, R.M.; Paull, B.; Breadmore, M.C. 3D printed microfluidic devices: Enablers and barriers. Lab Chip 2016, 16, 1993-2013. [CrossRef] [PubMed]

41. McDonald, J.C.; Chabinyc, M.L.; Metallo, S.J.; Anderson, J.R.; Stroock, A.D.; Whitesides, G.M. Prototyping of microfluidic devices in poly(dimethylsiloxane) using solid-object printing. Anal. Chem. 2002, 74, 1537-1545. [CrossRef] [PubMed]

42. Bhattacharjee, N.; Urrios, A.; Kang, S.; Folch, A. The upcoming 3D-printing revolution in microfluidics. Lab Chip 2016, 16, 1720-1742. [CrossRef] [PubMed]

43. Moore, J.L.; McCuiston, A.; Mittendorf, I.; Ottway, R.; Johnson, R.D. Behavior of capillary valves in centrifugal microfluidic devices prepared by three-dimensional printing. Microfluid. Nanofluidics 2011, 10, 877-888. [CrossRef]

44. Kitson, P.J.; Symes, M.D.; Dragone, V.; Cronin, L. Combining 3D printing and liquid handling to produce user-friendly reactionware for chemical synthesis and purification. Chem. Sci. 2013, 4, 3099-3103. [CrossRef]

45. Kitson, P.J.; Rosnes, M.H.; Sans, V.; Dragone, V.; Cronin, L. Configurable 3D-Printed millifluidic and microfluidic "lab on a chip" reactionware devices. Lab Chip 2012, 12, 3267-3271. [CrossRef] [PubMed]

46. He, Y.; Qiu, J.; Fu, J.; Zhang, J.; Ren, Y.; Liu, A. Printing 3D microfluidic chips with a 3D sugar printer. Microfluid. Nanofluidics 2015, 19, 447-456. [CrossRef]

47. Gelber, M.K.; Bhargava, R. Monolithic multilayer microfluidics via sacrificial molding of 3D-printed isomalt. Lab Chip 2015, 15, 1736-1741. [CrossRef] [PubMed]

48. Kadimisetty, K.; Mosa, I.M.; Malla, S.; Satterwhite-Warden, J.E.; Kuhns, T.M.; Faria, R.C.; Lee, N.H.; Rusling, J.F. 3D-printed supercapacitor-powered electrochemiluminescent protein immunoarray. Biosens. Bioelectron. 2016, 77, 188-193. [CrossRef] [PubMed]

49. Urrios, A.; Parra-Cabrera, C.; Bhattacharjee, N.; Gonzalez-Suarez, A.M.; Rigat-Brugarolas, L.G.; Nallapatti, U.; Samitier, J.; Deforest, C.A.; Posas, F.; Garcia-Cordero, J.L.; et al. 3D-printing of transparent bio-microfluidic devices in PEG-DA. Lab Chip 2016, 16, 2287-2294. [CrossRef] [PubMed]

50. Zhang, R.; Larsen, N.B. Stereolithographic hydrogel printing of 3D culture chips with biofunctionalized complex 3D perfusion networks. Lab Chip 2017, 17, 4273-4282. [CrossRef] [PubMed]

51. Soman, P.; Chung, P.H.; Zhang, A.P.; Chen, S. Digital microfabrication of user-defined 3D microstructures in cell-laden hydrogels. Biotechnol. Bioeng. 2013, 110, 3038-3047. [CrossRef] [PubMed]

52. Bhargava, K.C.; Thompson, B.; Malmstadt, N. Discrete elements for 3D microfluidics. Proc. Natl. Acad. Sci. USA 2014, 111, 15013-15018. [CrossRef] [PubMed]

53. Gong, H.; Woolley, A.T.; Nordin, G.P. High density 3D printed microfluidic valves, pumps, and multiplexers. Lab Chip 2016, 16, 2450-2458. [CrossRef] [PubMed]

54. Tumbleston, J.R.; Shirvanyants, D.; Ermoshkin, N.; Janusziewicz, R.; Johnson, A.R.; Kelly, D.; Chen, K.; Pinschmidt, R.; Rolland, J.P.; Ermoshkin, A.; Samulski, E.T.; DeSimone, J.M. Continuous liquid interface production of 3D objects. Science 2015, 347, 1349-1352. [CrossRef] [PubMed]

55. Na, K.; Shin, S.; Lee, H.; Shin, D.; Baek, J.; Kwak, H.; Park, M.; Shin, J.; Hyun, J. Effect of solution viscosity on retardation of cell sedimentation in DLP 3D printing of gelatin methacrylate/silk fibroin bioink. J. Ind. Eng. Chem. 2018, 61, 340-347. [CrossRef] 
56. Tanodekaew, S.; Channasanon, S.; Uppanan, P. Preparation and degradation study of photocurable oligolactide-HA composite: A potential resin for stereolithography application. J. Biomed. Mater. Res. Part B Appl. Biomater. 2014, 102, 604-611. [CrossRef] [PubMed]

57. Macdonald, N.P.; Zhu, F.; Hall, C.J.; Reboud, J.; Crosier, P.S.; Patton, E.E.; Wlodkowic, D.; Cooper, J.M. Assessment of biocompatibility of 3D printed photopolymers using zebrafish embryo toxicity assays. Lab Chip 2016, 16, 291-297. [CrossRef] [PubMed]

58. Bertsch, A.; Heimgartner, S.; Cousseau, P.; Renaud, P. Static micromixers based on large-scale industrial mixer geometry. Lab Chip 2001, 1, 56. [CrossRef] [PubMed]

59. Lee, W.; Kwon, D.; Choi, W.; Jung, G.Y.; Au, A.K.; Folch, A.; Jeon, S. Erratum: Corrigendum: 3D-Printed Microfluidic Device for the Detection of Pathogenic Bacteria Using Size-based Separation in Helical Channel with Trapezoid Cross-Section. Sci. Rep. 2015, 5, 9701. [CrossRef] [PubMed]

60. Shallan, A.I.; Smejkal, P.; Corban, M.; Guijt, R.M.; Breadmore, M.C. Cost-Effective Three-Dimensional Printing of Visibly Transparent Microchips within Minutes. Anal. Chem. 2014, 86, 3124-3130. [CrossRef] [PubMed]

61. Miller, P.R.; Gittard, S.D.; Edwards, T.L.; Lopez, D.M.; Xiao, X.; Wheeler, D.R.; Monteiro-Riviere, N.A.; Brozik, S.M.; Polsky, R.; Narayan, R.J. Integrated carbon fiber electrodes within hollow polymer microneedles for transdermal electrochemical sensing. Biomicrofluidics 2011, 5, 013415. [CrossRef] [PubMed]

62. Ong, L.J. Y.; Islam, A.; DasGupta, R.; Iyer, N.G.; Leo, H.L.; Toh, Y.-C. A 3D printed microfluidic perfusion device for multicellular spheroid cultures. Biofabrication 2017, 9, 045005. [CrossRef] [PubMed]

63. Credi, C.; Levi, M.; Turri, S.; Simeone, G. Stereolithography of perfluoropolyethers for the microfabrication of robust omniphobic surfaces. Appl. Surf. Sci. 2017, 404, 268-275. [CrossRef]

64. Gong, H.; Bickham, B.P.; Woolley, A.T.; Nordin, G.P. Custom 3D printer and resin for $18 \mu \mathrm{m} \times 20 \mu \mathrm{m}$ microfluidic flow channels. Lab Chip 2017, 17, 2899-2909. [CrossRef] [PubMed]

65. Kim, Y.; Castro, K.; Bhattacharjee, N.; Folch, A. Digital Manufacturing of Selective Porous Barriers in Microchannels Using Multi-Material Stereolithography. Micromachines 2018, 9, 125. [CrossRef]

66. He, Y.; Wu, Y.; Fu, J.; Gao, Q.; Qiu, J. Developments of 3D Printing Microfluidics and Applications in Chemistry and Biology: A Review. Electroanalysis 2016, 28, 1658-1678. [CrossRef]

67. Pilipović, A.; Raos, P.; Šercer, M. Experimental analysis of properties of materials for rapid prototyping. Int. J. Adv. Manuf. Technol. 2009, 40, 105-115. [CrossRef]

68. Anderson, K.B.; Lockwood, S.Y.; Martin, R.S.; Spence, D.M. A 3D Printed Fluidic Device that Enables Integrated Features. Anal. Chem. 2013, 85, 5622-5626. [CrossRef] [PubMed]

69. Paydar, O.H.; Paredes, C.N.; Hwang, Y.; Paz, J.; Shah, N.B.; Candler, R.N. Characterization of 3D-printed microfluidic chip interconnects with integrated O-rings. Sens. Actuators A Phys. 2014, 205, 199-203. [CrossRef]

70. Keating, S.J.; Gariboldi, M.I.; Patrick, W.G.; Sharma, S.; Kong, D.S.; Oxman, N. 3D printed multimaterial microfluidic valve. PLOS ONE 2016, 11, 1-12. [CrossRef] [PubMed]

71. Hwang, Y.; Paydar, O.H.; Candler, R.N. 3D printed molds for non-planar PDMS microfluidic channels. Sens. Actuators A Phys. 2015, 226, 137-142. [CrossRef]

72. Gowers, S.A.N.; Curto, V.F.; Seneci, C.A.; Wang, C.; Anastasova, S.; Vadgama, P.; Yang, G.-Z.; Boutelle, M.G. 3D Printed Microfluidic Device with Integrated Biosensors for Online Analysis of Subcutaneous Human Microdialysate. Anal. Chem. 2015, 87, 7763-7770. [CrossRef] [PubMed]

73. Sochol, R.D.; Sweet, E.; Glick, C.C.; Venkatesh, S.; Avetisyan, A.; Ekman, K.F.; Raulinaitis, A.; Tsai, A.; Wienkers, A.; Korner, K.; et al. 3D printed microfluidic circuitry via multijet-based additive manufacturing. Lab Chip 2016, 16, 668-678. [CrossRef] [PubMed]

74. Malinauskas, M.; Farsari, M.; Piskarskas, A.; Juodkazis, S. Ultrafast laser nanostructuring of photopolymers: A decade of advances. Phys. Rep. 2013, 533, 1-31. [CrossRef]

75. Sugioka, K.; Xu, J.; Wu, D.; Hanada, Y.; Wang, Z.; Cheng, Y.; Midorikawa, K. Femtosecond laser 3D micromachining: a powerful tool for the fabrication of microfluidic, optofluidic, and electrofluidic devices based on glass. Lab Chip 2014, 14, 3447-3458. [CrossRef] [PubMed]

76. Wu, D.; Niu, L.-G.; Wu, S.-Z.; Xu, J.; Midorikawa, K.; Sugioka, K. Ship-in-a-bottle femtosecond laser integration of optofluidic microlens arrays with center-pass units enabling coupling-free parallel cell counting with a 100\% success rate. Lab Chip 2015, 15, 1515-1523. [CrossRef] [PubMed] 
77. Sugioka, K.; Cheng, Y. Ultrafast lasers—reliable tools for advanced materials processing. Light Sci. Appl. 2014, 3, e149. [CrossRef]

78. Harriott, L.R. Limits of lithography. Proc. IEEE 2001, 89, 366-374. [CrossRef]

79. Zolotoyabko, E. Diffraction Phenomena in Optics. In Basics Concepts of X-ray Diffraction; John Wiley \& Sons, Inc.: Hoboken, NJ, USA, 2014; pp. 5-10.

80. Bjorkholm, J.E. EUV Lithography-The Successor to Optical Lithography? Intel Technol. J. 1998, 3, 1-8.

81. Stulen, R.H.; Sweeney, D.W. Extreme ultraviolet lithography. IEEE J. Quantum Electron. 1999, 35, $694-699$. [CrossRef]

82. UV Lithography: Taking Extreme Measures. Available online: https://www.nist.gov/news-events/news/ 2011/12/uv-lithography-taking-extreme-measures (accessed on 1 February 2018).

83. Xi, Y.; Zhang, W.; Fan, Z.; Ma, Q.; Wang, S.; Ma, D.; Jiang, Z.; Li, H.; Zhang, Y. A facile synthesis of silicon nanowires/micropillars structure using lithography and metal-assisted chemical etching method. J. Solid State Chem. 2018, 258, 181-190. [CrossRef]

84. Fallica, R.; Kirchner, R.; Schift, H.; Ekinci, Y. High-resolution grayscale patterning using extreme ultraviolet interference lithography. Microelectron. Eng. 2017, 177, 1-5. [CrossRef]

85. GN News Story. IBM Developed A Fingernail-Sized Chip That Holds 30 Billion Transistors. Available online: https://gineersnow.com/industries/ibm-developed-fingernail-sized-chip-holds-30billion-transistors (accessed on 1 February 2018).

86. Courtland, R. The molten tin solution. IEEE Spectr. 2016, 53. [CrossRef]

87. Altissimo, M. E-beam lithography for micro-/nanofabrication. Biomicrofluidics 2010, 4, 2-7. [CrossRef] [PubMed]

88. Kolodziej, C.M.; Maynard, H.D. Electron-beam lithography for patterning biomolecules at the micron and nanometer scale. Chem. Mater. 2012, 24, 774-780. [CrossRef]

89. Mali, P.; Sarkar, A.; Lal, R. Facile fabrication of microfluidic systems using electron beam lithography. Lab Chip 2006, 6, 310. [CrossRef] [PubMed]

90. Moolman, M.C.; Huang, Z.; Krishnan, S.T.; Kerssemakers, J.W. J.; Dekker, N.H. Electron beam fabrication of a microfluidic device for studying submicron-scale bacteria. J. Nanobiotechnol. 2013, 11, 1-10. [CrossRef] [PubMed]

91. Moffitt, J.R.; Lee, J.B.; Cluzel, P. The single-cell chemostat: An agarose-based, microfluidic device for high-throughput, single-cell studies of bacteria and bacterial communities. Lab Chip 2012, 12, 1487. [CrossRef] [PubMed]

92. Davies, J. Advantest to Showcase Advanced and Emerging Test Solutions at SEMICON Korea, January 31-February 2 in Seoul. Available online: https://globenewswire.com/news-release/2018/01/24/1304091/ 0/en/Advantest-to-Showcase-Advanced-and-Emerging-Test-Solutions-at-SEMICON-Korea-January-31February-2-in-Seoul.html (accessed on 1 February 2018).

93. Isobe, G.; Kanno, I.; Kotera, H.; Yokokawa, R. Perfusable multi-scale channels fabricated by integration of nanoimprint lighography (NIL) and UV lithography (UVL). Microelectron. Eng. 2012, 98, 58-63. [CrossRef]

94. Cross, G.L.W. The production of nanostructures by mechanical forming. J. Phys. D Appl. Phys. 2006, 39. [CrossRef]

95. Japan: Canon Developing Semiconductor Lithography Equipment Employing Nanoimprint Technology. Available online: http://link.galegroup.com/apps/doc/A403070922/AONE?u=marriottlibrary\&sid= AONE\&xid=df755ec8 (accessed on 1 February 2018).

96. Xia, Q.; Pease, R.F. Nanoimprint lithography 20 years on. Nanotechnology 2015, 26, 1-3. [CrossRef] [PubMed]

97. Hutfles, J.; Chapman, W.; Pellegrino, J. Roll-to-roll nanoimprint lithography of ultrafiltration membrane. J. Appl. Polym. Sci. 2018, 135, 1-12. [CrossRef]

98. Keller, F.; Hunter, M.S.; Robinson, D.L. Structural Features of Oxide Coatings on Aluminum. J. Electrochem. Soc. 1953, 100, 411. [CrossRef]

99. Masuda, H.; Fukuda, K. Ordered Metal Nanohole Arrays Made by a Two-Step Replication of Honeycomb Structures of Anodic Alumina. Science 1995, 268, 1466-1468. [CrossRef] [PubMed]

100. Hamouda, F.; Sahaf, H.; Held, S.; Barbillon, G.; Gogol, P.; Moyen, E.; Aassime, A.; Moreau, J.; Canva, M.; Lourtioz, J.M.; et al. Large area nanopatterning by combined anodic aluminum oxide and soft UV-NIL technologies for applications in biology. Microelectron. Eng. 2011, 88, 2444-2446. [CrossRef] 
101. Jo, H.; Haberkorn, N.; Pan, J.A.; Vakili, M.; Nielsch, K.; Theato, P. Fabrication of chemically tunable, hierarchically branched polymeric nanostructures by multi-branched anodic aluminum oxide templates. Langmuir 2016, 32, 6437-6444. [CrossRef] [PubMed]

102. Mireles, M.; Gaborski, T.R. Fabrication techniques enabling ultrathin nanostructured membranes for separations. Electrophoresis 2017, 38, 2374-2388. [CrossRef] [PubMed]

103. Sharma, R.; Gale, B.K. Electrochemical quantification of DNA using aluminum oxide membranes. Procedia Eng. 2011, 25, 713-716. [CrossRef]

104. Kim, J.; Gale, B.K. Quantitative and qualitative analysis of a microfluidic DNA extraction system using a nanoporous AlOx membrane. Lab Chip 2008, 8, 1516. [CrossRef] [PubMed]

105. Chen, G.; Wang, Y.; Wang, H.; Cong, M.; Chen, L.; Yang, Y.; Geng, Y.; Li, H.; Xu, S.; Xu, W. A highly sensitive microfluidics system for multiplexed surface-enhanced Raman scattering (SERS) detection based on Ag nanodot arrays. RSC Adv. 2014, 4, 54434-54440. [CrossRef]

106. Sochol, R.D.; Sweet, E.; Glick, C.C.; Wu, S.-Y.; Yang, C.; Restaino, M.; Lin, L. 3D printed microfluidics and microelectronics. Microelectron. Eng. 2018, 189, 52-68. [CrossRef]

(C) 2018 by the authors. Licensee MDPI, Basel, Switzerland. This article is an open access article distributed under the terms and conditions of the Creative Commons Attribution (CC BY) license (http://creativecommons.org/licenses/by/4.0/). 